\title{
Calculating the azimuth of mountain waves, using the effect of tilted fine-scale stable layers on VHF radar echoes
}

\author{
Richard M. Worthington \\ Department of Physics, University of Wales, Aberystwyth, Dyfed, SY23 3BZ, UK
}

Received: 19 November 1997 / Revised: 24 June 1998 / Accepted: 30 June 1998

\begin{abstract}
A simple method is described, based on standard VHF wind-profiler data, where imbalances of echo power between four off-vertical radar beams, caused by mountain waves, can be used to calculate the orientation of the wave pattern. It is shown that the mountain wave azimuth (direction of the horizontal component of the wavevector), is given by the vector $\left[\overline{\boldsymbol{W}\left(\boldsymbol{P}_{\mathrm{E}}-\boldsymbol{P}_{\mathrm{W}}\right)}, \overline{\boldsymbol{W}\left(\boldsymbol{P}_{\mathrm{N}}-\boldsymbol{P}_{\mathrm{S}}\right)}\right] ; \boldsymbol{P}_{\mathrm{N}}, \boldsymbol{P}_{\mathrm{S}}, \boldsymbol{P}_{\mathrm{E}}, \boldsymbol{P}_{\mathrm{W}}$ are radar echo powers, measured in $\mathrm{dB}$, in beams pointed away from vertical by the same angle towards north, south, east and west respectively, and $\boldsymbol{W}$ is the vertical wind velocity. The method is applied to Aberystwyth MST radar data, and the calculated wave vector usually, but not always, points into the low-level wind direction. The mean vertical wind at Aberystwyth, which may also be affected by tilted aspect-sensitive layers, is investigated briefly using the entire radar output 1990-1997. The mean vertical-wind profile is inconsistent with existing theories, but a new mountain-wave interpretation is proposed.
\end{abstract}

Key words. Meteorology and atmospheric dynamics (middle atmosphere dynamics; waves and tides; instruments and techniques).

\section{Introduction}

The power of VHF radar echoes from clear air almost always depends on the radar beam pointing angle. Echoes from a vertically pointing radar beam are usually most powerful, because of anisotropic backscattering, e.g. specular-type reflections such as Fresnel scatter from fine-scale horizontal layers in the atmospheric temperature structure (Dalaudier et al., 1994; Luce et al., 1995; Hocking and Hamza, 1997). In contrast, when a radar beam is pointed more than $\sim 15-20^{\circ}$ from zenith (Tsuda et al., 1997a), relatively weak echoes are returned from isotropic turbulence. Dependence of echo power on beam zenith angle is known as 'aspect sensitivity'.

It is also reported sometimes that aspect-sensitive radar-scattering layers can become tilted, for instance by gravity waves, with typical angles up to $\sim 1-2^{\circ}$ from horizontal (e.g. Röttger et al., 1990). Recently, this possibility has become relevant to wind profiler measurements:

1. When scattering layers are tilted from horizontal by the 'universal spectrum' of gravity waves, the distribution of the layer tilt angles may explain the way that VHF radar echo power decreases, when a radar beam is pointed away from the zenith (Tsuda et al., 1997a).

2. VHF wind profilers can measure vertical wind with excellent height and time resolutions. However, tilted scatterers might corrupt the vertical-beam measurements, by introducing a component of the horizontal wind (Larsen and Röttger, 1991). Similarly, measurements of the zonal, meridional and vertical velocity perturbations of gravity waves will be modified as the gravity waves themselves tilt the radarscattering layers.

3 . The long-term mean vertical wind, measured by wind profilers throughout the world, is usually found to be a few $\mathrm{cm} \mathrm{s}^{-1}$ downward in the troposphere, and often upward in the stratosphere. This is not always believed to be genuine. In one of several interpretations, Muschinski (1996) suggests how tilted scattering layers, caused by Kelvin-Helmholtz Instabilities in regions of jet-stream wind shear, can create a bias in the mean vertical-wind measurement.

4. Wind shear caused by long-period waves in the lower stratosphere is associated with an unexpected imbalance between the echo powers of symmetric radar beams. Tilting of aspect-sensitive scatterers, caused by the onset of Kelvin-Helmholtz Instability (KHI) in the 
long-period waves, may explain this power imbalance (Worthington and Thomas, 1996a, 1997).

5. When measuring aspect sensitivity, e.g. the parameter $\theta_{\text {s }}$ (Hocking et al., 1986; Jain et al., 1997) or the anisotropy (Pepler et al., 1998), the azimuthal variation of echo power is often assumed to be negligible. However, tilted scattering layers can cause differences between echo powers of beams pointed at the same zenith angle, but in different azimuths (Tsuda et al., 1997b); such variations of echo power can be almost as large as those between the beams at different zenith angles which are used to calculate aspect sensitivity. Azimuth dependence must therefore be taken into account, e.g. by using beams at several different zenith and azimuth angles.

The 'tilted scattering layer' model of Tsuda et al. (1997a, b), Worthington and Thomas (1997) (hereafter WT97) and Muschinski (1996) can be tested in new situations where tilted layers might also be expected, for example, mountain-wave events. Instead of the onset of KHI in high wind-shear conditions causing tilted layers (WT97), in this study it is mainly the mountain waves that tilt the air flow and the scattering layers from horizontal, producing echo power imbalances, as shown later. Cross sections showing the tilting of potential temperature surfaces by mountain waves have been published by e.g. Elkhalfi and Carissimo (1993).

Mountain-wave azimuth (i.e. the direction of the horizontally projected wavevector) influences the occurrence of critical-layer absorption, wave drag, and trapping (e.g. Shutts, 1995, 1997). Traditionally, wave azimuth can be found from the orientation of cloud bands, data from aircraft campaigns (Shutts and Broad, 1993), or combined aircraft, balloon and VHF radar comparisons (Caccia et al., 1997), but never before by VHF radar alone. In theory, the azimuth might be derivable from mountain-wave perturbations of the horizontal wind, but usually it is impossible to isolate the mountain-wave wind component from the spectrum of other gravity waves. Radar vertical-wind measurements, although sometimes dominated by mountain waves, give no direct information about the wave azimuth. However, it is shown later that imbalances of echo power between four off-vertical radar beams, combined with vertical-wind data, may be used to calculate the wave azimuth and its variation as a function of altitude and time. Usually, VHF radar only gives a vertical profile of the atmosphere directly above the radar site, but this new method shows how radar data can suggest more of the full 3-dimensional structure of mountain waves.

In numerical forecasting of mountain lee wave events, Shutts (1997) considers waves that might be generated within $\pm 60^{\circ}$ of the low level wind azimuth; this $120^{\circ}$ uncertainty is large enough that azimuth calculations by radar, such as in Sect. 4, may be useful. Also, the results shown later are consistent with WT97, where power imbalances between beam pairs at both $6^{\circ}$ and $12^{\circ}$ from zenith are interpreted in terms of tilted aspect-sensitive layers, and this helps to confirm that there is a specular-type contribution to radar echoes at surprisingly large beam zenith angles.

\section{Tilted aspect-sensitive scattering layers}

Figure 1 shows a schematic picture of tilted scattering layers, and the resulting imbalances of echo power, following WT97. The roughness of the layers obeys a $-5 / 3$ power law for their vertical displacement, following the model of Tsuda et al. (1997a). In Fig. 1a, the tilted aspect-sensitive layers are nearly perpendicular to

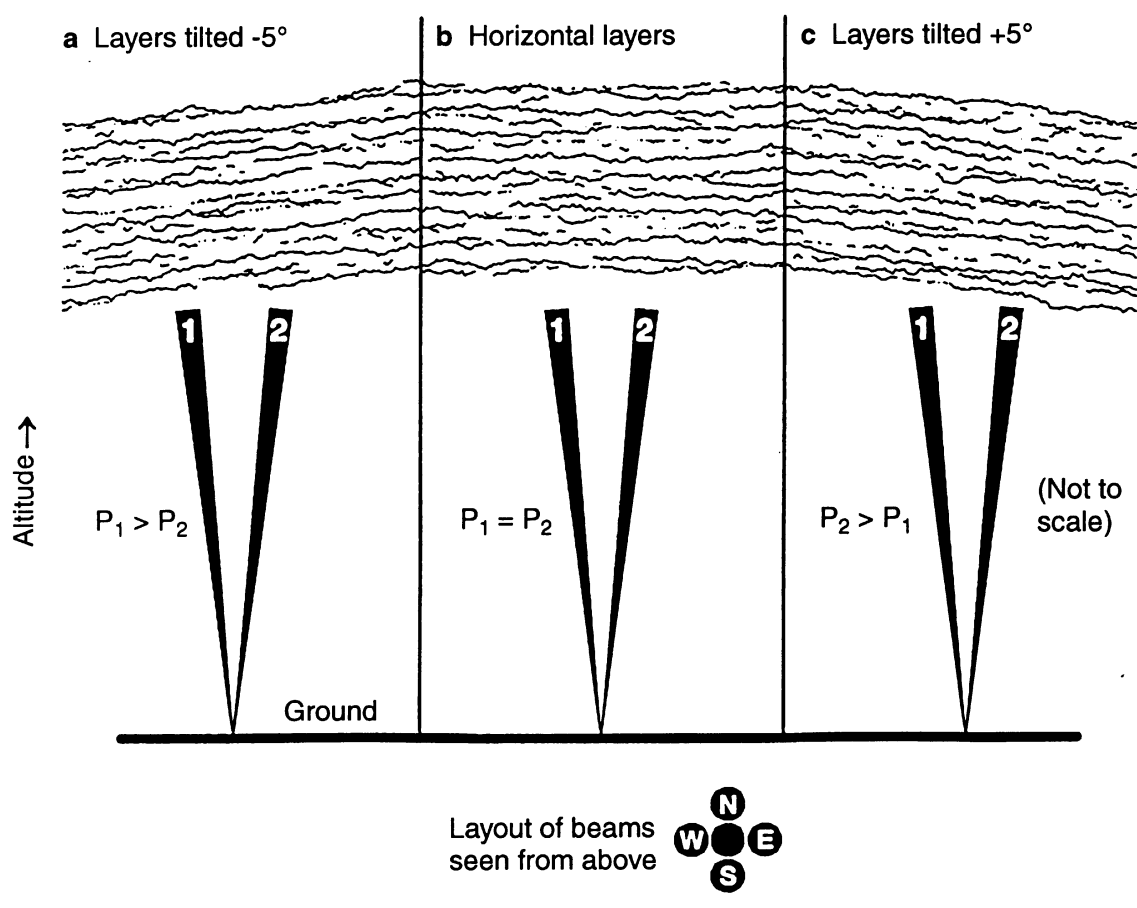

Fig. 1 a-c. Schematic diagram of tilted aspectsensitive scattering layers and their effect on the echo powers, $P_{1}$ and $P_{2}$, of a symmetric pair of radar beams. A standard 5-beam layout seen from above is also shown. In a the scatterers are nearly perpendicular to beam 1 and far from perpendicular to beam 2, so the echo power is greatest in beam 1 . The layers are on average horizontal in $\mathbf{b}$, so the echo powers in the two beams are approximately equal 
beam 1, and far from perpendicular to beam 2, so the echo power is greatest in beam 1 . (The $\pm 5^{\circ}$ tilt angles are exaggerated for clarity; one or two degrees would often be more typical for small-amplitude mountain waves.) Note that, even in Fig. 1b where the layers are on average horizontal, there are small regions with larger tilt angles from horizontal; according to WT97, there is a small specular contribution to radar echoes from beams with large zenith angles, e.g. $12^{\circ}$, implying that some scattering layers are tilted to similarly large angles from horizontal.

Figure 2 shows a typical radar 5-beam arrangement, with four beams pointed off-vertical by an equal angle towards north, south, east and west. The beams probe a region of atmosphere where scattering layers are tilted in a $\mathrm{N}-\mathrm{S}$ direction by an angle $\delta$ from horizontal, but are not tilted in the $\mathrm{E}-\mathrm{W}$ direction. This situation could occur if there is a mountain wave pattern above the radar, with its horizontal wave vector in the $\mathrm{N}-\mathrm{S}$ azimuth, i.e. its phase fronts and cloud bands aligned $\mathrm{E}-$ $\mathrm{W}$. The magnitude and sign of $\delta$ depend on the phase of the region of mountain wave above the radar; $\delta$ can be positive, negative or zero, and Fig. 2 represents a 'snapshot' where $\delta$ takes one particular (non-zero) value.

Echo power in Fig. 2 would be increased in the $\mathrm{S}$ beam, and decreased in the $\mathrm{N}$ beam, compared to the

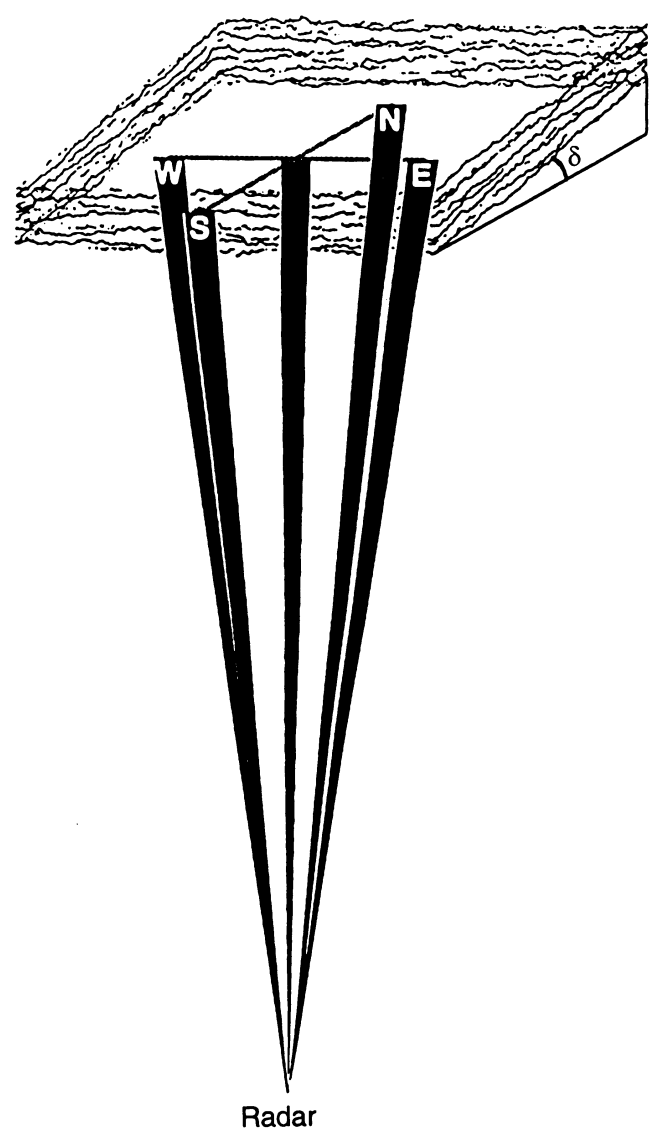

Fig. 2. Schematic diagram showing a 5-beam radar arrangement, and scattering layers tilted in a $\mathrm{N}-\mathrm{S}$ direction, but not $\mathrm{E}-\mathrm{W}$, which would give an echo power imbalance between $\mathrm{N}$ and $\mathrm{S}$ beams, but not between $\mathrm{E}$ and $\mathrm{W}$ beams radar echoes from horizontal scattering layers, as discussed for Fig. 1. The power imbalance $\left(\boldsymbol{P}_{\mathrm{N}}-\boldsymbol{P}_{\mathrm{S}}\right)$ would be negative $\left(\boldsymbol{P}_{\mathrm{N}}, \boldsymbol{P}_{\mathrm{S}}, \boldsymbol{P}_{\mathrm{E}}, \boldsymbol{P}_{\mathrm{W}}\right.$ are echo powers, measured in $\mathrm{dB}$, for the beams pointed towards north, south, east and west respectively.) In contrast, the power imbalance $\left(\boldsymbol{P}_{\mathrm{E}}-\boldsymbol{P}_{\mathrm{W}}\right)$ would be zero, since there is no difference in the effective zenith angle of $\mathrm{E}$ and $\mathrm{W}$ beams - their geometry is symmetric about a $\mathrm{N}-\mathrm{S}$ vertical plane.

Considering, instead, a situation with the mountain wave vector aligned $\mathrm{E}-\mathrm{W}$ (phase fronts and cloud bands $\mathrm{N}-\mathrm{S})$, the power imbalance $\left(\boldsymbol{P}_{\mathrm{N}}-\boldsymbol{P}_{\mathrm{S}}\right)$ would now become zero, and $\left(\boldsymbol{P}_{\mathrm{E}}-\boldsymbol{P}_{\mathrm{W}}\right)$ non-zero. As summarised in Table 1, the relative size of the power imbalances $\left(\boldsymbol{P}_{\mathrm{E}}-\boldsymbol{P}_{\mathrm{W}}\right)$ and $\left(\boldsymbol{P}_{\mathrm{N}}-\boldsymbol{P}_{\mathrm{S}}\right)$ might be used to estimate crudely the orientation of a mountain-wave pattern above a radar, to an accuracy of $\sim 45^{\circ}$. However, an analytical method derived in Sect. 3 uses the exact relative sizes of $\left(\boldsymbol{P}_{\mathrm{N}}-\boldsymbol{P}_{\mathrm{S}}\right)$ and $\left(\boldsymbol{P}_{\mathrm{E}}-\boldsymbol{P}_{\mathrm{W}}\right)$ to calculate the azimuth of the mountain wave vector.

\section{Calculating mountain-wave azimuth}

\subsection{Basic method}

Assume a mountain-wave pattern that tilts aspectsensitive atmospheric structures, such as fine-scale stable layers, which can give VHF radar echoes. The scattering layers above a VHF radar are tilted by an angle $\delta$ from horizontal; usually, $\delta$ varies with altitude, and, since the mountain-wave pattern moves and changes above the radar (Ralph et al., 1997; Worthington and Thomas, 1998), $\delta$ will also vary with time. The horizontal wavelength of mountain waves, typically $\sim 10-30 \mathrm{~km}$, is much greater than the region spanned by the radar beams $\left(\sim 2 \mathrm{~km}\right.$ between a pair of $6^{\circ}$ beams at $10 \mathrm{~km}$ altitude) so the layers, although tilted from horizontal, are assumed to be plane and not curved. This assumption is checked in the Appendix.

A radar beam pointed away from the zenith, towards north (e.g. the ' $\mathrm{N}$ ' beam in Fig. 2), has the unit vector $(0, \sin \theta, \cos \theta)$, where $\theta$ is its zenith angle. Cartesian coordinates $(x, y, z)$ are used, with positive $x$ towards east, positive $y$ towards north, and positive $z$ upwards. For a tilted plane, with its north side inclined upward from the horizontal by an angle $\delta$, and then rotated (about a vertical axis) through an azimuth angle $\phi$ clockwise from north (Fig. 2 shows the case where $\phi=0$ ), the unit vector perpendicular to the plane is $(-\sin \phi \sin \delta$,

Table 1.

\begin{tabular}{|c|c|c|}
\hline & & Power imbalances \\
\hline & & $\left(\boldsymbol{P}_{E}-\boldsymbol{P}_{W}\right)$ \\
\hline $\begin{array}{l}\text { Mountain-wave } \\
\text { azimuth }\end{array}$ & $\begin{array}{l}\text { NW-SE } \\
\text { N-S } \\
\text { NE-SW } \\
\text { E-W }\end{array}$ & $\begin{array}{l}\text { Equal magnitudes, but opposite signs } \\
+,-, \text { or zero Always zero } \\
\text { Equal magnitudes, same signs } \\
\text { Always zero } \quad+,-, \text { or zero }\end{array}$ \\
\hline
\end{tabular}


$-\cos \phi \sin \delta, \cos \delta)$. The scalar product of these two unit vectors, $-\sin \theta \cos \phi \sin \delta+\cos \theta \cos \delta$, gives the cosine of the angle, $\Theta$, between them. If the plane is that of the aspect-sensitive layers above the radar, having been tilted from horizontal by mountain waves propagating in azimuth $\phi$, the nominal beam zenith angle $\theta$ will be modified to:

$\Theta=\cos ^{-1}(-\sin \theta \cos \phi \sin \delta+\cos \theta \cos \delta)$

or equivalently,

$\Theta=\frac{\pi}{2}-\sin ^{-1}(-\sin \theta \cos \phi \sin \delta+\cos \theta \cos \delta)$

i.e., $\Theta$ would be the beam zenith angle, if the radar beam and scattering layers were, together, reorientated to restore the tilted scattering layers to being horizontal. If $\theta=6^{\circ}$ and $\delta=1^{\circ}$, for example, then a mountain wave azimuth of $\phi=0^{\circ}, 90^{\circ}, 180^{\circ}, 270^{\circ}$ gives $\Theta=7^{\circ}, 6.08^{\circ}$, $5^{\circ}, 6.08^{\circ}$ respectively. The results for $\phi=0^{\circ}$ and $180^{\circ}$, where $\Theta=6+1^{\circ}$ and $6-1^{\circ}$ respectively, might be expected. However, the result $\Theta=6.08^{\circ}$ for $\phi=90^{\circ}$ and $270^{\circ}$, i.e. layers tilted $\mathrm{E}-\mathrm{W}$, but radar beam pointed $\mathrm{N}$ or $\mathrm{S}$, is less obvious. Note also that the effective zenith angle for line-of-sight velocity measurements would be modified further, since aspect sensitivity pulls the effective beam pointing angle nearer to being perpendicular to the scattering layers; e.g. for horizontal layers, the beam is pulled toward the zenith. However, this complication can be ignored here, since only the relation of echo power to $\Theta$ is being used.

For a beam zenith angle $\Theta$ of, e.g. $6^{\circ}$, the dependence of echo power, in $\mathrm{dB}$, on $\Theta$ can be assumed approximately linear over a range of a few degrees either side of $6^{\circ}$ (e.g. Tsuda et al., 1997b). The imbalance of echo power between a symmetric pair of radar beams, measured in $\mathrm{dB}$, is therefore

$$
\begin{aligned}
& \boldsymbol{D}_{1 \mathrm{w}}= P(\theta, \phi, \delta)-P(-\theta, \phi, \delta) \\
& \approx A\left[-\sin ^{-1}(-\sin \theta \cos \phi \sin \delta+\cos \theta \cos \delta)\right. \\
&\left.\quad+\sin ^{-1}(\sin \theta \cos \phi \sin \delta+\cos \theta \cos \delta)\right]
\end{aligned}
$$

where $P$ is radar echo power, and $A$ is the gradient of echo power with respect to $\Theta$, in $\mathrm{dB}$ per degree (typically between -0.5 and $-2.0 \mathrm{~dB} \mathrm{deg}^{-1}$; Tsuda et al. (1997a) and Jain et al. (1997) report -1.25 and $-1.2 \mathrm{~dB} \mathrm{deg}^{-1}$ respectively). The subscript ' $w$ ' indicates that these power imbalances are assumed to be caused by mountain waves only.

For a beam pair in the orthogonal east-west azimuth (in effect, an azimuth of $\phi+\frac{\pi}{2}$ instead of $\phi$ for the pair of radar beams, or $\phi-\frac{\pi}{2}$ instead of $\phi$ for the tilted plane), the power imbalance becomes

$$
\begin{aligned}
\boldsymbol{D}_{2 \mathrm{w}}= & P(\theta, \phi+\pi / 2, \delta)-P(-\theta, \phi+\pi / 2, \delta) \\
\approx A[ & -\sin ^{-1}(-\sin \theta \sin \phi \sin \delta+\cos \theta \cos \delta) \\
& \left.\quad+\sin ^{-1}(\sin \theta \sin \phi \sin \delta+\cos \theta \cos \delta)\right]
\end{aligned}
$$

The dependence of $A$ on azimuth, caused by other factors such as a strong jetstream (Yoe et al., 1994) is assumed to be small here. So, Eqs (2) and (3) give

$$
\begin{aligned}
& \boldsymbol{D}_{1 \mathrm{w}}=A\left[\sin ^{-1}(a+c)-\sin ^{-1}(-a+c)\right] \\
& \boldsymbol{D}_{2 \mathrm{w}}=A\left[\sin ^{-1}(b+c)-\sin ^{-1}(-b+c)\right]
\end{aligned}
$$

where $\quad a=\sin \theta \cos \phi \sin \delta, \quad b=\sin \theta \sin \phi \sin \delta \quad$ and $c=\cos \theta \cos \delta$. The inverse sine terms can be expanded (e.g. Abramowitz and Stegun, 1965) since

$\sin ^{-1} z=z+\frac{1}{2 \cdot 3} z^{3}+\frac{1 \cdot 3}{2 \cdot 4 \cdot 5} z^{5}+\frac{1 \cdot 3 \cdot 5}{2 \cdot 4 \cdot 6 \cdot 7} z^{7}+\ldots$

Note that the small-angle approximation (the limiting case being $\sin ^{-1} z \approx z \approx \sin z$, as $z \rightarrow 0$ ) cannot be used here; $(a+c),(-a+c),(b+c)$ and $(-b+c)$ are all near 1 , implying 'large' angles near $\pi / 2$. Combining Eqs. (4), (5), (6) gives

$$
\begin{aligned}
\boldsymbol{D}_{1 \mathrm{w}}=A( & {[(a+c)-(-a+c)] } \\
& \left.+\frac{1}{6}\left[(a+c)^{3}-(-a+c)^{3}\right]+\ldots\right) \\
\boldsymbol{D}_{2 \mathrm{w}}=A( & {[(b+c)-(-b+c)] } \\
& \left.+\frac{1}{6}\left[(b+c)^{3}-(-b+c)^{3}\right]+\ldots\right)
\end{aligned}
$$

If Eqs. (7) and (8) are expanded, all terms containing even powers of $a$ or $b$ (e.g. $a^{0} c^{3}$ and $-a^{0} c^{3}$, or $3 a^{2} c$ and $-3 a^{2} c$ ) cancel out within each pair of square brackets. Since any value of $\phi$ and all realistically small values of $\theta$ and $\delta$ give $a \approx 0, b \approx 0$ and $c \approx 1$, terms containing higher powers of $a$ or $b$ very rapidly approach zero, irrespective of the power of $c$ that is multiplied with them. The significant terms in Eq. (7) are of order $a^{1}$ and $b^{1}$, and neglecting terms of orders $a^{3}, b^{3}, a^{5}, b^{5}$ and higher introduces an error of only a few percent to $\boldsymbol{D}_{1 \mathrm{w}}$ and $\boldsymbol{D}_{2 \mathrm{w}}$, according to numerical testing. Retaining only the 1 st order terms leaves

$$
\boldsymbol{D}_{1 \mathrm{w}}=\boldsymbol{A}\left(2 a+a c^{2}+\frac{3}{4} a c^{4}+\frac{3}{4} \cdot \frac{5}{6} a c^{6}+\frac{3}{4} \cdot \frac{5}{6} \cdot \frac{7}{8} a c^{8}+\ldots\right)
$$

and

$\boldsymbol{D}_{2 \mathrm{w}}=\boldsymbol{A}\left(2 b+b c^{2}+\frac{3}{4} b c^{4}+\frac{3}{4} \cdot \frac{5}{6} b c^{6}+\frac{3}{4} \cdot \frac{5}{6} \cdot \frac{7}{8} b c^{8}+\ldots\right)$

which slowly converge toward the exact values given by Eqs. (2) and (3). Separating the terms with a $\phi$ dependence gives

$$
\boldsymbol{D}_{1 \mathrm{w}}=\left[\boldsymbol{A} \sin \theta \sin \delta\left(2+c^{2}+\frac{3}{4} c^{4}+\frac{5}{8} c^{6}+\ldots\right)\right] \cos \phi
$$

and

$$
\boldsymbol{D}_{2 \mathrm{w}}=\left[\boldsymbol{A} \sin \theta \sin \delta\left(2+c^{2}+\frac{3}{4} c^{4}+\frac{5}{8} c^{6}+\ldots\right)\right] \sin \phi
$$

i.e., the vector $\left(\boldsymbol{D}_{2 \mathrm{w}}, \boldsymbol{D}_{1 \mathrm{w}}\right)$, or

$$
\left(\left(\boldsymbol{P}_{\mathrm{E}}-\boldsymbol{P}_{\mathrm{W}}\right),\left(\boldsymbol{P}_{\mathrm{N}}-\boldsymbol{P}_{\mathrm{S}}\right)\right)
$$

has the same azimuth as the scattering layers tilted by mountain waves, $(\sin \phi, \cos \phi)$, without any need for 
information on the exact tilt angle $\delta$ of the scattering layers, the aspect sensitivity parameter $A$, or even the nominal beam zenith angle $\theta$. Note that $\boldsymbol{D}_{1 \mathrm{w}}$ and $\boldsymbol{D}_{2 \mathrm{w}}$ are measured in $\mathrm{dB}$, since in Eqs. (2) and (3) it is the echo power in $d B$ that is approximately a linear function of beam zenith angle $\Theta$ in degrees, following Tsuda et al. (1997b). The non-dependence on $\delta$ means that the calculated azimuth is independent of the phase of the mountain wave above the radar, except that the most reliable estimate will be possible when power imbalances, and hence $\delta$ and the vertical wind, are largest. As $\delta \rightarrow 0$ the power imbalances become too small to measure reliably. The method given by Eq. (11) has, independently, been applied empirically to mesospheric VHF radar data by J. Y. N. Cho et al. (private communication, 1998), and the results interpreted in terms of the tilt angles of scattering layers.

\subsection{Adapting the method for mountain waves}

In practice, it can be difficult to measure reliable instantaneous values of $\left(\boldsymbol{P}_{\mathrm{E}}-\boldsymbol{P}_{\mathrm{W}}\right)$ and $\left(\boldsymbol{P}_{\mathrm{N}}-\boldsymbol{P}_{\mathrm{S}}\right)$, since other factors such as vertical shear of horizontal wind also cause power imbalances (WT97). It is usually not possible to average $\left(\boldsymbol{P}_{\mathrm{E}}-\boldsymbol{P}_{\mathrm{W}}\right)$ or $\left(\boldsymbol{P}_{\mathrm{N}}-\boldsymbol{P}_{\mathrm{S}}\right)$ over a few hours, since mountain waves are not steady above the radar, and the time-variations of $\boldsymbol{W}$, often changing between positive and negative $\boldsymbol{W}$, indicate that the tilt angle of the region of mountain wave above the radar is varying (Worthington and Thomas, 1998). Consequently, the power imbalances $\boldsymbol{D}_{2 \mathrm{w}}=\left(\boldsymbol{P}_{\mathrm{E}}-\boldsymbol{P}_{\mathrm{W}}\right)$ and $\boldsymbol{D}_{1 \mathrm{w}}=\left(\boldsymbol{P}_{\mathrm{N}}-\boldsymbol{P}_{\mathrm{S}}\right)$ will, over time, tend to average to zero. And, although Eq. (11) does give the azimuth in which the layers are tilted, the calculated mountainwave azimuth still has a $180^{\circ}$ ambiguity.

All of these problems can be avoided using $\boldsymbol{W}$, which is dominated by mountain waves, as a reference to find the contribution to the power imbalances which is caused only by mountain waves. The relative size of the mountain-wave contributions to $\left(\boldsymbol{P}_{\mathrm{N}}-\boldsymbol{P}_{\mathrm{S}}\right)$ and $\left(\boldsymbol{P}_{\mathrm{E}}-\boldsymbol{P}_{\mathrm{W}}\right)$ can then give the orientation of the wave pattern.

Considering the quantities $\overline{\boldsymbol{W D}}_{1}$ and $\overline{\boldsymbol{W D}}_{2}$, Eqs. (9) and (10) give

$$
\begin{aligned}
\overline{\boldsymbol{W} \boldsymbol{D}_{1 \mathrm{w}}}= & \overline{\boldsymbol{W} \boldsymbol{A} \sin \theta \sin \delta\left(2+c^{2}+\frac{3}{4} c^{4}+\frac{5}{8} c^{6}+\ldots\right)} \\
& \times \cos \phi
\end{aligned}
$$

and

$$
\begin{aligned}
\overline{\boldsymbol{W} \boldsymbol{D}_{2 \mathrm{w}}}= & \overline{\boldsymbol{W} \boldsymbol{A} \sin \theta \sin \delta\left(2+c^{2}+\frac{3}{4} c^{4}+\frac{5}{8} c^{6}+\ldots\right)} \\
& \times \sin \phi
\end{aligned}
$$

where the overbar indicates averaging over an interval of height and/or time. The only terms with a $\phi$ dependence in Eqs. (12) or (13), $\cos \phi$ and $\sin \phi$, can be taken outside the average since they are both assumed constants over the height-time averaging interval.

Unlike $\overline{\boldsymbol{D}_{1 \mathrm{w}}}$ and $\overline{\boldsymbol{D}_{2 \mathrm{w}}}, \overline{\boldsymbol{W} \boldsymbol{A} \sin \theta \sin \delta\left(2+c^{2}+\frac{3}{4} c^{4}+\right.}$ $\overline{\left.\frac{5}{8} c^{6}+\ldots\right)}$ and hence $\overline{\boldsymbol{W} \boldsymbol{D}_{1 \mathrm{w}}}$ and $\overline{\boldsymbol{W} \boldsymbol{D}_{2 \mathrm{w}}}$ can be shown not to average to zero. Of the terms in Eqs (12) and (13), only $\boldsymbol{W}$ and $\sin \delta$ change sign as a function of altitude and/or time. The relation between $\boldsymbol{W}$ and $\sin \delta$, i.e. $\boldsymbol{W}=\boldsymbol{U} \sin \delta$, and hence $\boldsymbol{W} \sin \delta=\boldsymbol{U} \sin ^{2} \delta$, where $\boldsymbol{U}$ is the horizontal wind speed, determines the values that Eqs. (12) and (13) average to. $\boldsymbol{U}$ does not remain steady, but does not usually reverse direction with time, or with height either, which would imply a critical layer for the mountain waves; the variations of the sign of $\boldsymbol{W}$, e.g. in Fig. 4a, are mainly caused by the changing $\delta$ of the region of mountain waves above the radar (Worthington and Thomas, 1998). Since $\sin ^{2} \delta$ must be positive or zero, and $\boldsymbol{U}$ does not change sign, $\boldsymbol{U} \sin ^{2} \delta$ cannot change sign within the averaging interval, and $\overline{\boldsymbol{W} \boldsymbol{A} \sin \theta \sin \delta\left(2+c^{2}+\frac{3}{4} c^{4}+\frac{5}{8} c^{6}+\ldots\right)}$ in Eqs. (12) and (13) will average to a positive or negative number, but not to zero. Even if the magnitude of $\boldsymbol{W}$ is reduced, because the effective pointing angle of the vertical beam is pulled towards being perpendicular to the aspectsensitive scatterers, this would not change the sign of the $\boldsymbol{W}$ measurement.

Equations (12), (13) therefore give

$$
\begin{aligned}
& \overline{\boldsymbol{W D}_{1 \mathrm{w}}}=\boldsymbol{B} \cos \phi \\
& \overline{\boldsymbol{W} \boldsymbol{D}_{2 \mathrm{w}}}=\boldsymbol{B} \sin \phi
\end{aligned}
$$

where $\boldsymbol{B}=\overline{\boldsymbol{W} \boldsymbol{A} \sin \theta \sin \delta\left(2+c^{2}+\frac{3}{4} c^{4}+\frac{5}{8} c^{6}+\ldots\right)}$ and $(\sin \phi, \cos \phi)$ gives the azimuth of the tilted layers, $\phi$ being measured clockwise from north. The azimuth of the mountain wave vector is the same as the azimuth of the calculated vector

$$
\mathbf{k}=\left(\overline{\boldsymbol{W} \boldsymbol{D}_{2 \mathrm{w}}}, \overline{\boldsymbol{W} \boldsymbol{D}_{1 \mathrm{w}}}\right) \text {. }
$$

The magnitude of vector $\mathbf{k}$ shows the combined effects of several factors - mainly, the aspect sensitivity and the amplitude of the mountain waves. Note that it is still assumed that $\boldsymbol{D}_{1 \mathrm{w}}$ and $\boldsymbol{D}_{2 \mathrm{w}}$ are caused by mountainwave tilting only; however, this assumption can now be relaxed.

A time series of the measured power imbalance at a given height, $\quad \boldsymbol{D}_{2}=\left(\boldsymbol{P}_{\mathrm{E}}-\boldsymbol{P}_{\mathrm{W}}\right)$ or $\boldsymbol{D}_{1}=\left(\boldsymbol{P}_{\mathrm{N}}-\boldsymbol{P}_{\mathrm{S}}\right)$, might be treated as a sum of two components, one caused by mountain-wave tilts, the other caused by a combination of the random measurement error, wind shears (WT97), and layer-tilting by other gravity waves. There is no reason to suspect that the mountain-wave power imbalances are correlated with those caused by random errors, shears and other gravity waves; assume therefore,

$$
\begin{aligned}
& \boldsymbol{D}_{1}=\boldsymbol{D}_{1 \mathrm{w}}+\boldsymbol{D}_{1 \mathrm{r}} \\
& \boldsymbol{D}_{2}=\boldsymbol{D}_{2 \mathrm{w}}+\boldsymbol{D}_{2 \mathrm{r}}
\end{aligned}
$$

where $\boldsymbol{D}_{1}$ and $\boldsymbol{D}_{2}$ are functions of both height and time, and the subscripts ' $w$ ' and ' $r$ ' refer to the 'mountain- 
wave' and the other 'random' components respectively. If $\boldsymbol{W}$ is similarly the sum of 'mountain-wave' and 'random' terms (although dominated by mountain waves in the examples shown later) then

$\boldsymbol{W}=\boldsymbol{W}_{\mathrm{w}}+\boldsymbol{W}_{\mathrm{r}}$.

The terms $\boldsymbol{W}_{\mathrm{w}}, \boldsymbol{W}_{\mathrm{r}}, \boldsymbol{D}_{1 \mathrm{w}}, \boldsymbol{D}_{1 \mathrm{r}}, \quad \boldsymbol{D}_{2 \mathrm{w}}$ and $\boldsymbol{D}_{2 \mathrm{r}}$ are assumed to be uncorrelated with each other, except $\boldsymbol{W}_{\mathrm{w}}, \boldsymbol{D}_{1 \mathrm{w}}$ and $\boldsymbol{D}_{2 \mathrm{w}}$ which are inter-related since the mountain-wave tilts cause both power imbalances $\boldsymbol{D}_{1 \mathrm{w}}$, $\boldsymbol{D}_{2 \mathrm{w}}$ and the non-zero vertical wind $\boldsymbol{W}_{\mathrm{w}}$. There might be some correlation between $\boldsymbol{W}_{\mathrm{r}}$ and $\boldsymbol{D}_{1 \mathrm{r}}$ or $\boldsymbol{D}_{2 \mathrm{r}}$, caused by other gravity waves. However, short period gravity-waves are usually quite azimuthally isotropic (e.g. Prichard and Thomas, 1993) so, for example, if north-propagating gravity waves cause $\overline{\boldsymbol{W D _ { 1 }}}$ to become more negative, this is balanced by southpropagating gravity waves causing $\overline{\boldsymbol{W D}_{1}}$ to become more positive, giving no overall power imbalance. If the gravity waves (other than mountain waves) are strongly azimuthally anisotropic, then this will affect the mountain-wave azimuth calculation. However, this would be showing the actual atmospheric processes and wave field that are present, rather than being a failure of the power-imbalance method. The effect of gravity waves with periods much longer than the averaging time, which may be more azimuthally anisotropic, can be removed by subtracting the means from $\boldsymbol{W}, \boldsymbol{D}_{1}$ and $\boldsymbol{D}_{2}$ before calculating $\overline{\boldsymbol{W D}_{1}}$ and $\overline{W D_{2}}$.

Expanding $\overline{\boldsymbol{W} \boldsymbol{D}_{1}}$ using Eqs. (17) and (19) gives

$$
\begin{aligned}
\overline{\boldsymbol{W} \boldsymbol{D}_{1}} & =\overline{\left(\boldsymbol{W}_{\mathrm{w}}+\boldsymbol{W}_{\mathrm{r}}\right)\left(\boldsymbol{D}_{1 \mathrm{w}}+\boldsymbol{D}_{1 \mathrm{r}}\right)} \\
& =\overline{\boldsymbol{W}_{\mathrm{w}} \boldsymbol{D}_{1 \mathrm{w}}+\boldsymbol{W}_{\mathrm{w}} \boldsymbol{D}_{1 \mathrm{r}}+\boldsymbol{W}_{\mathrm{r}} \boldsymbol{D}_{1 \mathrm{w}}+\boldsymbol{W}_{\mathrm{r}} \boldsymbol{D}_{1 \mathrm{r}}} \\
& =\overline{\boldsymbol{W}_{\mathrm{w}} \boldsymbol{D}_{1 \mathrm{w}}}+\overline{\boldsymbol{W}_{\mathrm{w}} \boldsymbol{D}_{1 \mathrm{r}}}+\overline{\boldsymbol{W}_{\mathrm{r}} \boldsymbol{D}_{1 \mathrm{w}}}+\overline{\boldsymbol{W}_{\mathrm{r}} \boldsymbol{D}_{1 \mathrm{r}}}
\end{aligned}
$$

where the last step is valid since the terms being averaged are summed over the same set of data points. The 2nd, 3rd and 4th terms in Eq. (20) average to zero, provided the 'random' terms are not correlated with each other, or with the 'mountain-wave' terms. After sufficient averaging, Eq. (20) therefore gives

$$
\overline{\boldsymbol{W D}}=\overline{\boldsymbol{W}_{\mathrm{w}} \boldsymbol{D}_{1 \mathrm{w}}}
$$

and similarly

$$
\overline{W D_{2}}=\overline{\boldsymbol{W}_{\mathrm{w}} \boldsymbol{D}_{2 \mathrm{w}}} \text {. }
$$

So, while Eq. (16) assumes that only mountain waves are present, Eqs. (21) and (22) show that real data containing power imbalances from other sources can be used instead, and will give the same answer for the calculated mountain-wave azimuth.

In summary, the mountain-wave azimuth is given by the vector

$\mathbf{k}=\left[\overline{\boldsymbol{W}\left(\boldsymbol{P}_{\mathrm{E}}-\boldsymbol{P}_{\mathrm{W}}\right)}, \overline{\boldsymbol{W}\left(\boldsymbol{P}_{\mathrm{N}}-\boldsymbol{P}_{\mathrm{S}}\right)}\right]$

where the two vector components are positive when towards $\mathrm{E}$ and $\mathrm{N}$, and the overbars indicate averaging over height and/or time.

\subsection{Summary of the method}

1. Need conditions of both aspect sensitivity and mountain-wave activity, and also standard 5-beam VHF radar data with measurements of vertical wind, and echo powers in four off-vertical directions (e.g. $\mathrm{N} 6^{\circ}$, $\left.\mathrm{E}^{\circ}, \mathrm{S}^{\circ}, \mathrm{W}^{\circ}\right)$. Calculate the echo power imbalances $\left(\boldsymbol{P}_{\mathrm{N}}-\boldsymbol{P}_{\mathrm{S}}\right)$ and $\left(\boldsymbol{P}_{\mathrm{E}}-\boldsymbol{P}_{\mathrm{W}}\right)$, the powers being measured in $\mathrm{dB}$.

2. Divide the data into blocks of a few $\mathrm{km}$ altitude $\times$ a few hours. Subtract the means of $\boldsymbol{W},\left(\boldsymbol{P}_{\mathrm{N}}-\boldsymbol{P}_{\mathrm{S}}\right)$ and $\left(\boldsymbol{P}_{\mathrm{E}}-\boldsymbol{P}_{\mathrm{W}}\right)$ from each data block.

3. Calculate the average quantities $\overline{\boldsymbol{W}\left(\boldsymbol{P}_{\mathrm{N}}-\boldsymbol{P}_{\mathrm{S}}\right)}$ and $\overline{\boldsymbol{W}\left(\boldsymbol{P}_{\mathrm{E}}-\boldsymbol{P}_{\mathrm{W}}\right)}$ for each data block.

4. The mountain-wave azimuth for each data block is given by the vector $\overline{\boldsymbol{W}\left(\boldsymbol{P}_{\mathrm{E}}-\boldsymbol{P}_{\mathrm{W}}\right)}, \overline{\boldsymbol{W}\left(\boldsymbol{P}_{\mathrm{N}}-\boldsymbol{P}_{\mathrm{S}}\right)}$. If the radar beams do not point exactly $\mathrm{N}, \mathrm{E}, \mathrm{S}, \mathrm{W}$, then the calculated azimuth will have an offset equal to the angle that the radar array is rotated from $\mathrm{N}, \mathrm{E}, \mathrm{S}, \mathrm{W}$, which can easily be subtracted.

\section{MST radar observations of mountain waves}

\subsection{Overview}

The results in Sect. 3 are now used both to apply and to test the tilted scattering layer model. Data are supplied by the Natural Environment Research Council 46.5 $\mathrm{MHz}$ radar near Aberystwyth, Wales $\left(52.4^{\circ} \mathrm{N}, 4.0^{\circ} \mathrm{W}\right)$, operating in 5-beam mode. Peak transmitted power is $160 \mathrm{~kW}$, duty cycle $2.5 \%$, one-way beamwidth $3^{\circ}$, time resolution $<5 \mathrm{~min}$, and pulse length $8 \mu \mathrm{s}$ with coding to give height resolution of either $300 \mathrm{~m}$ or $150 \mathrm{~m}$. Note that the radar beams are not aligned $\mathrm{N}, \mathrm{E}, \mathrm{S}, \mathrm{W}$, but instead $\mathrm{N} 62.3^{\circ} \mathrm{W}, \mathrm{E} 62.3^{\circ} \mathrm{N}, \mathrm{S} 62.3^{\circ} \mathrm{E}, \mathrm{W} 62.3^{\circ} \mathrm{S}$ (nominally NW, NE, SE, SW). The offset of $62.3^{\circ}$ is removed when the mountain-wave azimuth is calculated.

For mountains consisting of long parallel ridges, the mountain wave vector would tend to be perpendicular to the ridges (e.g. Mitchell et al., 1990), and not very dependent on low-level wind direction; in contrast, an isolated mountain peak generates a 'ship wave'-type pattern, containing a range of wave vectors (e.g. Simard and Peltier, 1982). Real mountains are usually more complex than simple ridges and peaks, often requiring, for example, a spectral description (Shutts, 1995). Some studies (e.g. Bacmeister, 1993) attempt to identify ridges from terrain maps, and thereby predict the mountain wave azimuth. However, Fig. 3 shows that the terrain upstream of the Aberystwyth MST radar is not dominated by clearly-defined two-dimensional ridges.

To investigate mountain-wave azimuth, three case studies are chosen, summarised below, all showing echo power imbalances caused by mountain waves, although the synoptic conditions are different.

- 4-9 January 1997. A low-level easterly wind persists for nearly a week and generates mountain waves in the troposphere, except for when a lull in wind speed reduces the mountain-wave activity for several hours in 


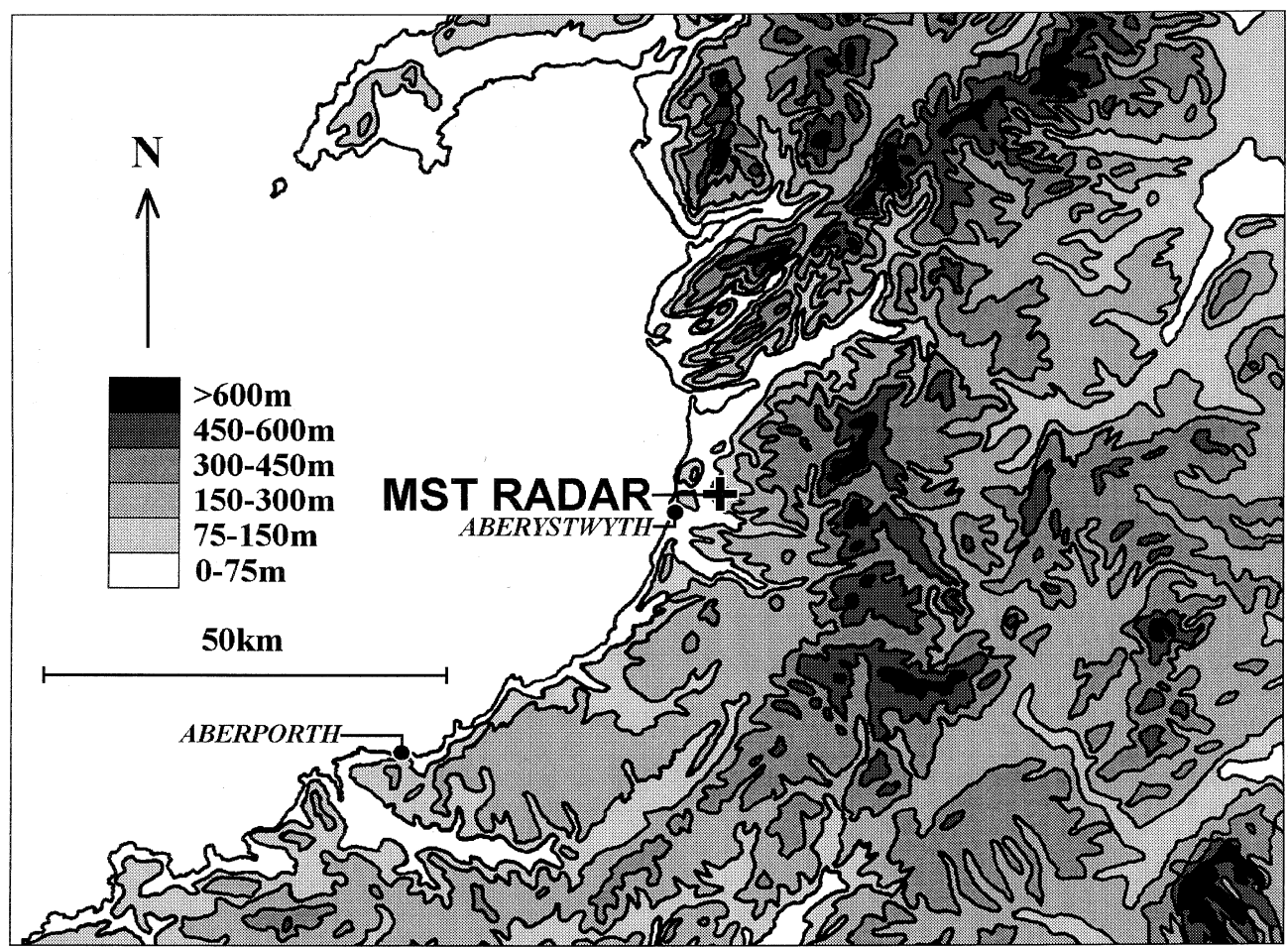

Fig. 3. Map showing mid-Wales, the sea, and the location of the Aberystwyth MST radar. Land height is given in metres. The low-level wind direction for the three case studies can be seen in Figs. $4 \mathrm{e}, 7 \mathrm{e}$, and $8 \mathrm{e}$ the middle of the event. The mountain waves break near $10 \mathrm{~km}$ altitude (e.g. Worthington and Thomas, 1996b). Aspect sensitivity in the troposphere is initially weak, but becomes stronger later, and echo-power imbalances then appear.

- 15-16 December 1993. A westerly low-level wind generates mountain waves which propagate into the stratosphere with no evidence of breaking. Aspect sensitivity is much stronger above the tropopause and, helped by the near-absence of inertia-gravity waves, power imbalances caused by the mountain waves can be seen in the lower stratosphere.

- 28-29 October 1997. The low-level wind is fairly weak, and its direction variable, but some mountain waves are generated in the troposphere. For a period of several hours on 29 October, the mountain wave vector points south, which is unexpected since the wind in the lowest radar height-gates is south-westerly at this time, i.e. the mountain waves appear to be generated at $45^{\circ}$ to the low-level wind azimuth. However further data from radiosondes suggest that this calculated wave azimuth is correct.

\subsection{Mountain-wave azimuth observations}

Beginning with 4-9 January 1997, Fig. 4a shows the vertical wind $\boldsymbol{W}$, with large perturbations indicating that the air flow is displaced from horizontal by mountainwave activity. Figure $4 \mathrm{~b}$ shows the anisotropy, i.e. the difference between vertical and off-vertical echo power, $\boldsymbol{P}_{\mathrm{VRT}}-\frac{1}{4}\left(\boldsymbol{P}_{\mathrm{NW} 6^{\circ}}+\boldsymbol{P}_{\mathrm{NE}^{\circ}}+\boldsymbol{P}_{\mathrm{SE} 6^{\circ}}+\boldsymbol{P}_{\mathrm{SW} 6^{\circ}}\right)$ where $\boldsymbol{P}$ is the echo power in the respective beam, measured in $\mathrm{dB}$. The four $6^{\circ}$ echo powers are averaged together, in an attempt to avoid here the dependence of echo power on azimuth which is introduced by mountain waves. The anisotropy is used as a measure of aspect sensitivity, instead of $\theta_{\mathrm{s}}$ which cannot be determined using only vertical and $6^{\circ}$ radar beam data (Hooper and Thomas, 1995). The lightest-shaded regions in Fig. 4b indicate the highest anisotropy, and hence strongest aspect sensitivity, e.g. in the stratosphere. Aspect-sensitive atmospheric conditions are needed for the method of Sect. 3 to work.

Figure 4c, d shows echo power imbalances, $\left(\boldsymbol{P}_{\mathrm{NW} 6^{\circ}}-\boldsymbol{P}_{\mathrm{SE} 6^{\circ}}\right)$ and $\left(\boldsymbol{P}_{\mathrm{NE} 6^{\circ}}-\boldsymbol{P}_{\mathrm{SW} 6^{\circ}}\right)$, which become most obviously non-zero when there are both mountain waves (Fig. 4a) and aspect sensitivity (Fig. 4b), e.g. in the troposphere at 90-120 h; the data appear consistent with the idea that tilted airflow which gives $\boldsymbol{W} \neq 0$ also tilts the radar scattering layers. The power imbalance in Fig. $4 c$ is correlated negatively with $\boldsymbol{W}$ in Fig. 4a; the power imbalance in Fig. 4d is weaker, and generally shows a positive correlation with $\boldsymbol{W}$. Figure $4 \mathrm{e}$ shows the background wind vectors, which are easterly at low levels, while Fig. 4f shows the mountain wave vectors calculated using the data from Fig. 4a, c, d and Eq. (23). In the unshaded region of Fig. $4 \mathrm{f}$, where there is both aspect sensitivity and mountain-wave activity, the standard errors on the arrows are very small. The wave vector azimuth points into the low-level horizontal wind direction. Note that the vectors are derived with no information about the horizontal wind direction, only the vertical wind and the $6^{\circ}$ echo powers are involved.

It would be useful to check the agreement of the wave azimuth calculated using different sets of off-vertical beams, measuring at the same time, e.g. $\left(\mathrm{NW}^{\circ}, \mathrm{NE}^{\circ}\right.$, $\left.\mathrm{SE}^{\circ}, \mathrm{SW}^{\circ}\right),\left(\mathrm{NW} 12^{\circ}, \mathrm{NE} 12^{\circ}, \mathrm{SE} 12^{\circ}, \mathrm{SW} 12^{\circ}\right),\left(\mathrm{N} 4.2^{\circ}\right.$, $\left.\mathrm{E} 4.2^{\circ}, \mathrm{S} 4.2^{\circ}, \mathrm{W} 4.2^{\circ}\right)$ and $\left(\mathrm{N} 8.5^{\circ}, \mathrm{E} 8.5^{\circ}, \mathrm{S} 8.5^{\circ}, \mathrm{W} 8.5^{\circ}\right)$ 
a Vertical wind $\left(\mathrm{m} \mathrm{s}^{-1}\right)$

04-09/01/97
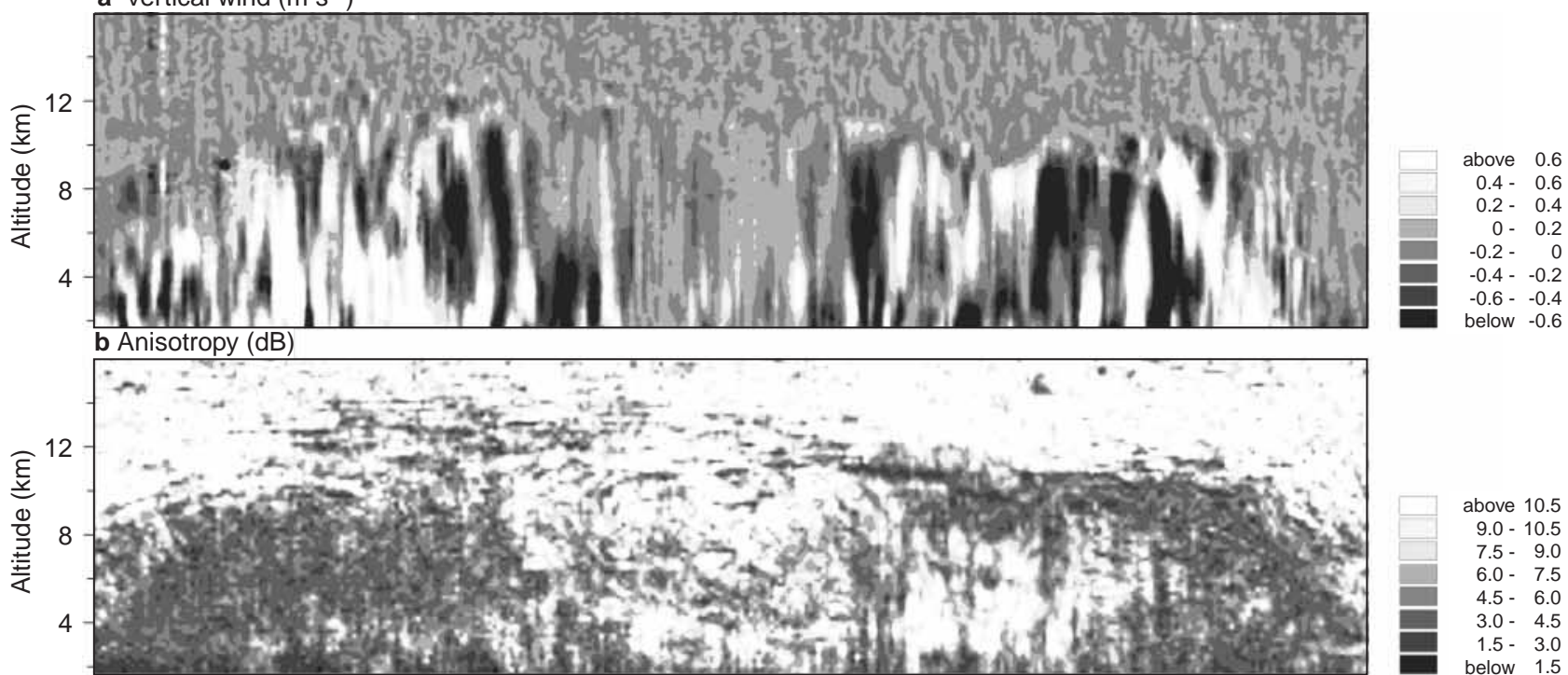

c Echo power imbalance NW6 ${ }^{\circ}-\mathrm{SE6}^{\circ}(\mathrm{dB})$

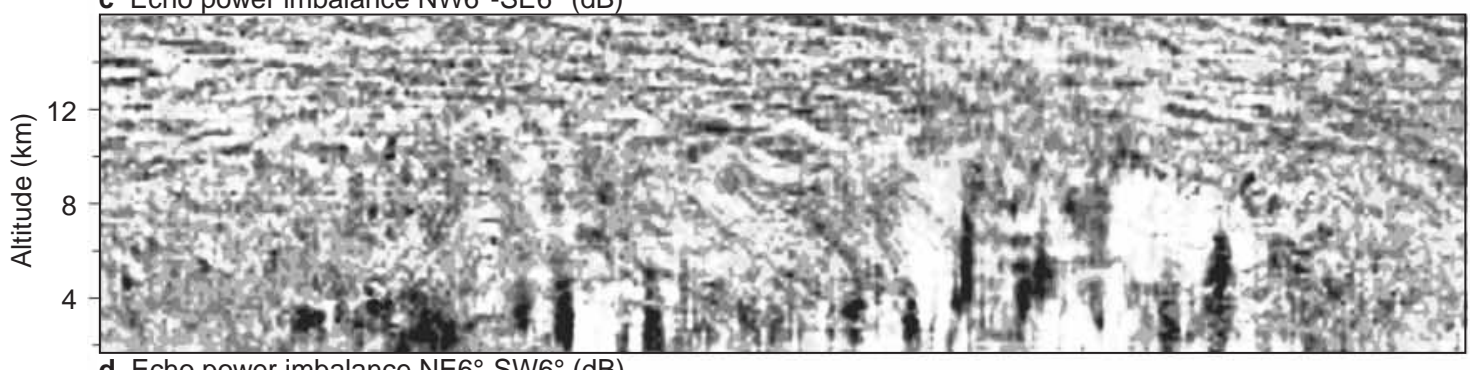

d Echo power imbalance $\mathrm{NE}^{\circ}-\mathrm{SW6}^{\circ}(\mathrm{dB})$

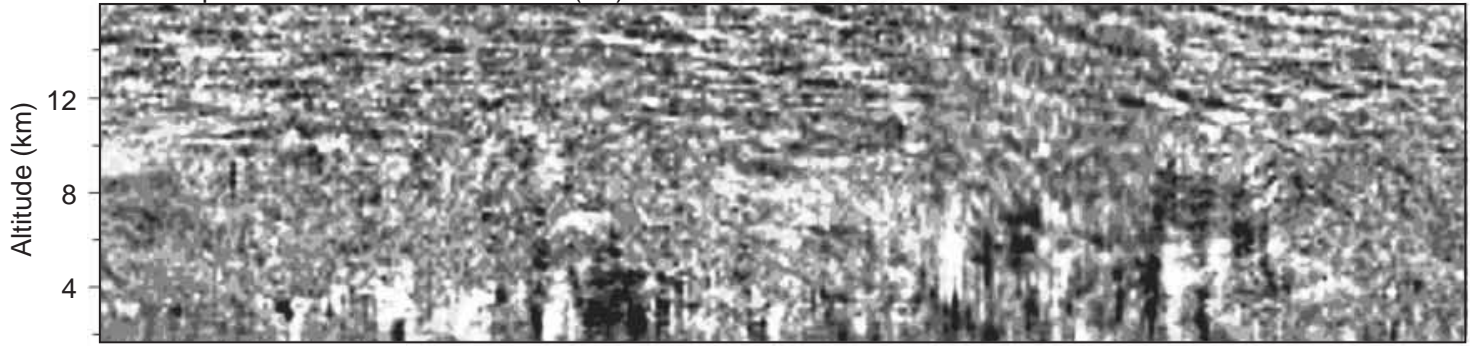

e Horizontal wind vectors
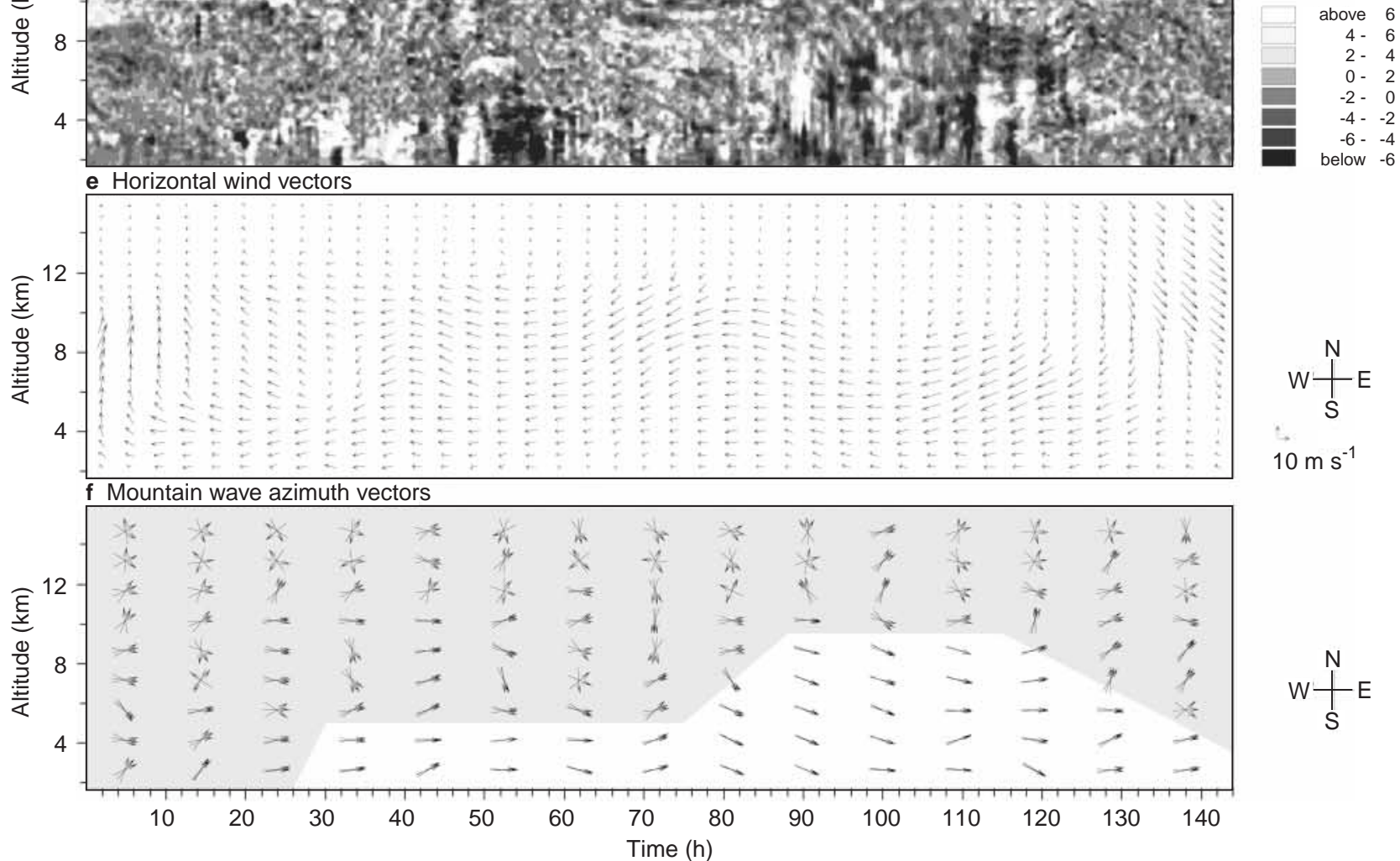

$10 \mathrm{~m} \mathrm{~s}^{-1}$

$w \stackrel{N}{T_{S}} E$ 
Fig. 4. a Height-time plot of vertical wind velocity, measured by a vertically pointing radar beam during a mountain-wave event on 4-9 January 1997; b anisotropy, i.e. the difference between vertical beam echo power, and the average of the $6^{\circ}$ beam echo powers, measured in $\mathrm{dB} ; \mathbf{c}$ imbalance of echo powers between symmetric $\mathrm{NW} 6^{\circ}$ and $\mathrm{SE} 6^{\circ}$ beams; $\mathbf{d}$ imbalance of echo powers between symmetric $N E 6^{\circ}$ and SW6 ${ }^{\circ}$ beams; e horizontal wind vectors; f mountain wave azimuth vectors, calculated using Eq. (23). An estimate of standard error is plotted, and the unshaded region shows where the method works best because of both aspect sensitivity and mountain-wave activity. The vector magnitude is set constant

for the Aberystwyth MST radar. The Aberystwyth radar can use only 8 different beams per cycle, and so this test is difficult to make; however this would, in future studies, help to show whether variations of wave azimuth with altitude, e.g. in Fig. 4f, are real. Note that other gravity waves also tilt the scattering layers as discussed earlier, and if these waves have a marked azimuth dependence, there could be calculated azimuth vectors with low standard errors outside the region of mountain-wave activity, or the calculated vectors might be modified in the region assumed to be dominated by mountain waves. However, in Fig. $4 \mathrm{f}$ for example, there are no arrows above the region of mountain-wave activity where this explanation might need to be invoked.

The separate values of $\left[\boldsymbol{W}\left(\boldsymbol{P}_{\mathrm{NW} 6^{\circ}}-\boldsymbol{P}_{\mathrm{SE} 6^{\circ}}\right)\right]$ and $\left[\boldsymbol{W}\left(\boldsymbol{P}_{\mathrm{NE} 6^{\circ}}-\boldsymbol{P}_{\mathrm{SW} 6^{\circ}}\right)\right]$, before being converted into vectors, are plotted in Fig. 5. Regions where $\left[\boldsymbol{W}\left(\boldsymbol{P}_{\mathrm{NW} 6^{\circ}}-\right.\right.$ $\left.\left.\boldsymbol{P}_{\mathrm{SE} 6^{\circ}}\right)\right]$ and $\left[\boldsymbol{W}\left(\boldsymbol{P}_{\mathrm{NE} 6^{\circ}}-\boldsymbol{P}_{\mathrm{SW} 6^{\circ}}\right)\right]$ are non-zero match up with conditions of simultaneous large vertical wind and aspect-sensitivity in Fig. 4a, b. At those phases of the mountain wave where the tilt $\delta$ (and hence $\boldsymbol{W}$ ) are near to zero, Fig. 5a, b shows values near zero as expected; when the scattering layers above the radar are horizontal, no information is available about the wave azimuth. As a check, if the data with small $|\boldsymbol{W}|$ are removed before calculating $\overline{\left[\boldsymbol{W}\left(\boldsymbol{P}_{\mathrm{NW} 6^{\circ}}-\boldsymbol{P}_{\left.\mathrm{SE} 6^{\circ}\right)}\right]\right.}$ and $\overline{\left[\boldsymbol{W}\left(\boldsymbol{P}_{\mathrm{NE6} 6^{\circ}}-\boldsymbol{P}_{\mathrm{SW} 6^{\circ}}\right)\right]}$ for each arrow in Fig. $4 \mathrm{f}$, e.g. with a cutoff requiring $|\boldsymbol{W}|>0.5 \mathrm{~m} \mathrm{~s}^{-1}$, there is very little change in the calculated wave azimuth. $\boldsymbol{W}$ can also be calculated from the average of the line-of-sight velocities in the off-vertical beams, i.e. $\boldsymbol{W} \approx\left(v_{\mathrm{NE} 6^{\circ}}+v_{\mathrm{SE}^{\circ}}+\right.$ $\left.v_{\mathrm{SW} 6^{\circ}}+v_{\mathrm{NW} 6^{\circ}}\right) /(4 \cos \theta)$.

Further information about mountain-wave orientation is available from wave clouds on satellite images. Figure 6 shows a visible-light satellite image taken at hour 110. The cloud bands appear to indicate trapped lee waves since, where revealed by the presence of the cloud bands, the waves are seen to persist downwind over the sea for several cycles. Their wavelength is approximately $5 \mathrm{~km}$. The radar and the satellite are, however, not detecting the same mountain waves, since radiosonde data indicate these trapped wave clouds are associated with a temperature inversion at $1.2 \mathrm{~km}$ altitude, which is below the region observable in Fig. 4. The air has very low humidity above $1.2 \mathrm{~km}$, and is nearly saturated below, the waves apparently trapped in a layer of high Scorer parameter at $1.2 \mathrm{~km}$. The wave vector in Fig. 6 (i.e. perpendicular to the cloud bands, and pointing into the wind) varies between NE and SE. Near the radar site, marked by a cross, the wave vector is towards ENE. However, Fig. 6 gives no information about the wavelength or azimuth of the untrapped tropospheric mountain waves in Fig. 4a, since there are no clouds above $1.2 \mathrm{~km}$ altitude. Both Fig. $4 \mathrm{f}$ and the low-level wind direction in Fig. 4e may suggest that the a Product of vertical wind and NW6 ${ }^{\circ}$-SE6 ${ }^{\circ}$ echo power imbalance $\left(\mathrm{m} \mathrm{s}^{-1} \mathrm{~dB}\right)$
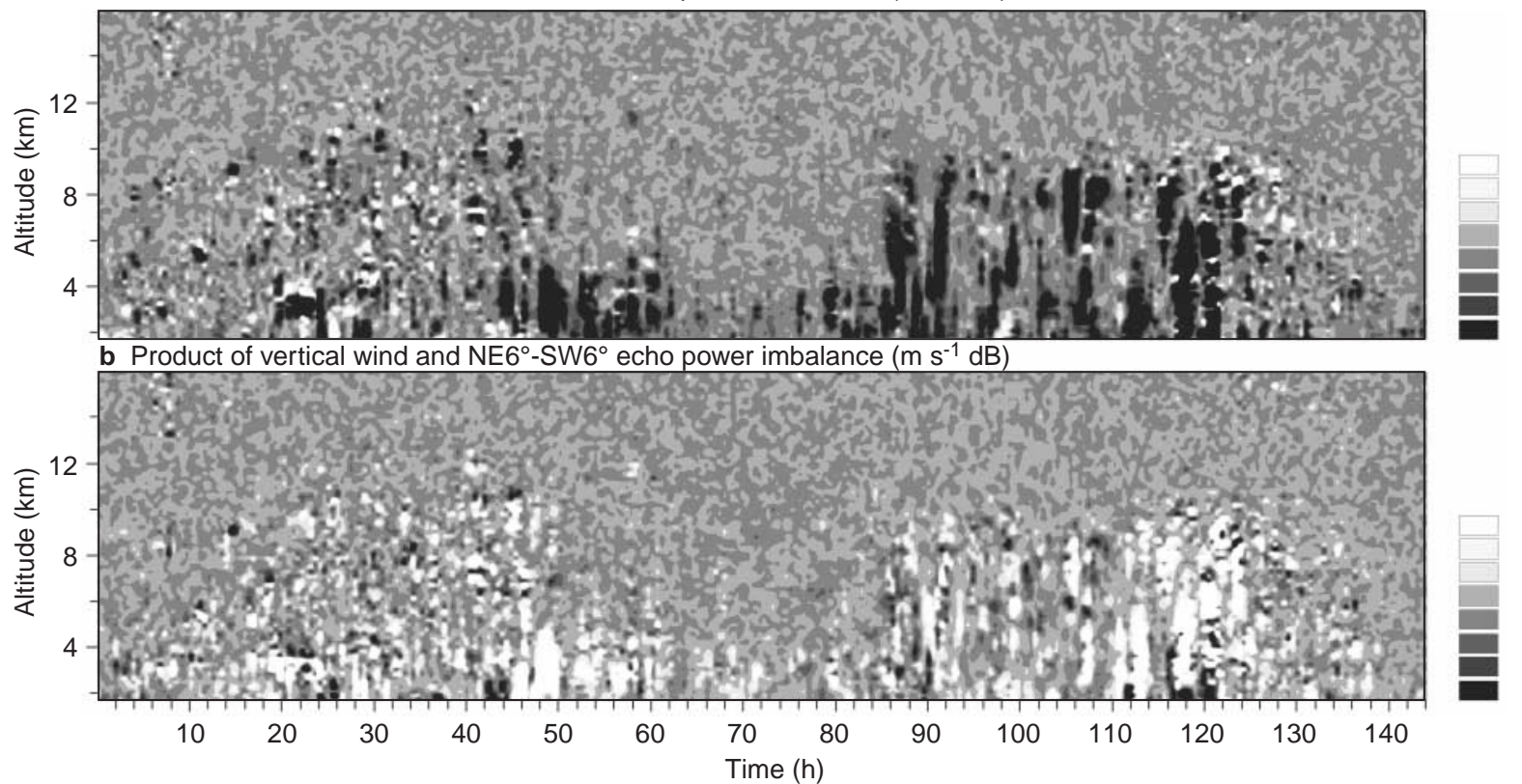

above 2.4

$1.6-2.4$

$0.8-1.6$

$0-0.8$

$-0.8-\quad 0$

$-1.6--0.8$

$-2.4--1.6$

below -2.4

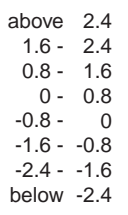

Fig. 5a ,b. Product of the vertical wind $\boldsymbol{W}$ and the power imbalances $\mathbf{a}\left(P_{\mathrm{NW} 6^{\circ}}-P_{\mathrm{SE} 6^{\circ}}\right)$ and $\mathbf{b}\left(\boldsymbol{P}_{\mathrm{NE} 6^{\circ}}-\boldsymbol{P}_{\mathrm{SW} 6^{\circ}}\right)$, before being converted into vectors for Fig. 4f 


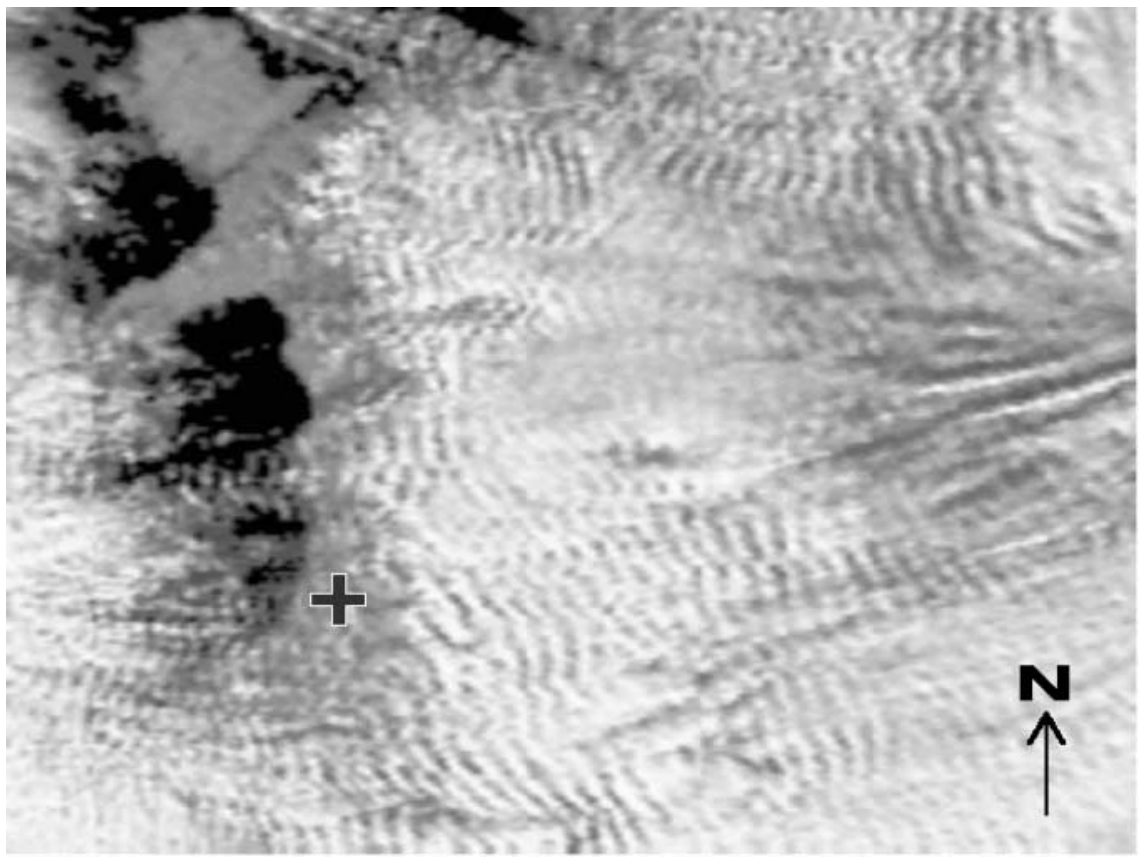

Fig. 6. Visible-light satellite image at 1333 GMT, 8 January 1997 (Courtesy of the University of Dundee). The MST radar site is marked by a cross. The coastline of northwest Wales can be seen in a cloud-free region downwind of the Welsh mountains wave vector of the tropospheric mountain waves points near to $\mathrm{E}$ rather than ENE. However, there is not sufficient evidence here to prove that the low-level trapped lee waves and the tropospheric mountain waves may have different azimuths.

Figure 7 shows the second case study, which has the benefit of strong aspect-sensitivity in the stratosphere. The hills are fairly low to the west and north-west, but maps with very much higher resolution than Fig. 1 (Ordnance Survey, 1987a, b) show there are many individual peaks of 100-180 m, the highest being Bryn hir $(179 \mathrm{~m}), 4 \mathrm{~km}$ from the radar. Prichard et al. (1995) have studied the generation of mountain waves observed above the Aberystwyth radar, and concluded that even the low hills to the west and north-west can produce large-amplitude mountain waves, similar to Fig. 7a. Figure $7 \mathrm{c}$, d, especially Fig. 7c, shows again how the power imbalances are only seen when aspect sensitivity is strong (WT97). This implies that factors such as horizontal gradients of horizontal wind (Larsen and Palmer, 1997), which can cause deviations of beam pointing angles, are not necessary to explain these data. Note that, in Fig. 7a, in addition to the slowly-changing mountain wave component, there are variations of $\boldsymbol{W}$ on shorter time scales down to $1 \mathrm{~h}$ or less (e.g. Worthington and Thomas, 1998), with associated changes in the power imbalances. In Fig. $7 \mathrm{c}$, in contrast to Fig. $4 \mathrm{c}$, $\left(\boldsymbol{P}_{\mathrm{NW} 6^{\circ}}-\boldsymbol{P}_{\mathrm{SE} 6^{\circ}}\right)$ and $\boldsymbol{W}$ are now positively, not negatively, correlated. The cloud cover on satellite images for 15-16 December 1993 does not show any wave clouds; however, the wave azimuth can be calculated throughout the lower stratosphere in Fig. 7f, showing that variations of azimuth with altitude are not more than a few tens of degrees.

Figure 8 shows the final case study; the low-level wind is initially from ESE, later from S and then SW.
The wave azimuth points towards ESE at first, and turns to remain facing into the low-level wind. However, after $\sim$ hour 30, the wave vector remains pointing S, and does not turn any further so as to point into the southwesterly background wind. Satellite images give no extra information, showing mostly clear skies and no wave clouds. To examine reasons for the wave vector perhaps pointing toward S, Fig. 9 plots the wind speed and direction measured by radiosondes, launched at Aberporth (see Fig. 3), each averaged over the altitude range 200-1000 m, which is below the range that the radar can measure. The last two sondes in Fig. 9 indicate the wind flow in the lowest $\mathrm{km}$ is nearly from S, not SW. Also, whereas there are only low hills and the Irish Sea SW of the radar, to the $S$ there are hills of several hundred metres (Fig. 3). For both these reasons, the S pointing of the calculated wave vector is not surprising, and may be correct. The wind speed below $1000 \mathrm{~m}$ is stronger than in the lowest radar height gates near $2 \mathrm{~km}$, and this is also more consistent with the generation of mountain waves.

\subsection{Tilted layers and the mean vertical wind}

As mentioned in Sect. 1, tilting of aspect-sensitive scattering layers has been invoked to explain unexpected observations of downward mean vertical wind $(\bar{W})$ in the troposphere, and upward $\bar{W}$ in the stratosphere (Muschinski, 1996), perhaps caused by the wind shear of different sign above and below the jet maximum near $10 \mathrm{~km}$. Other explanations have included real vertical winds associated with the jet stream (Fukao et al., 1991; Yoe and Rüster, 1992), and correlations between vertical-wind and reflectivity perturbations of gravity waves (Nastrom and VanZandt, 1994; Nastrom and Eaton, 1995), with a contribution also from antenna- 

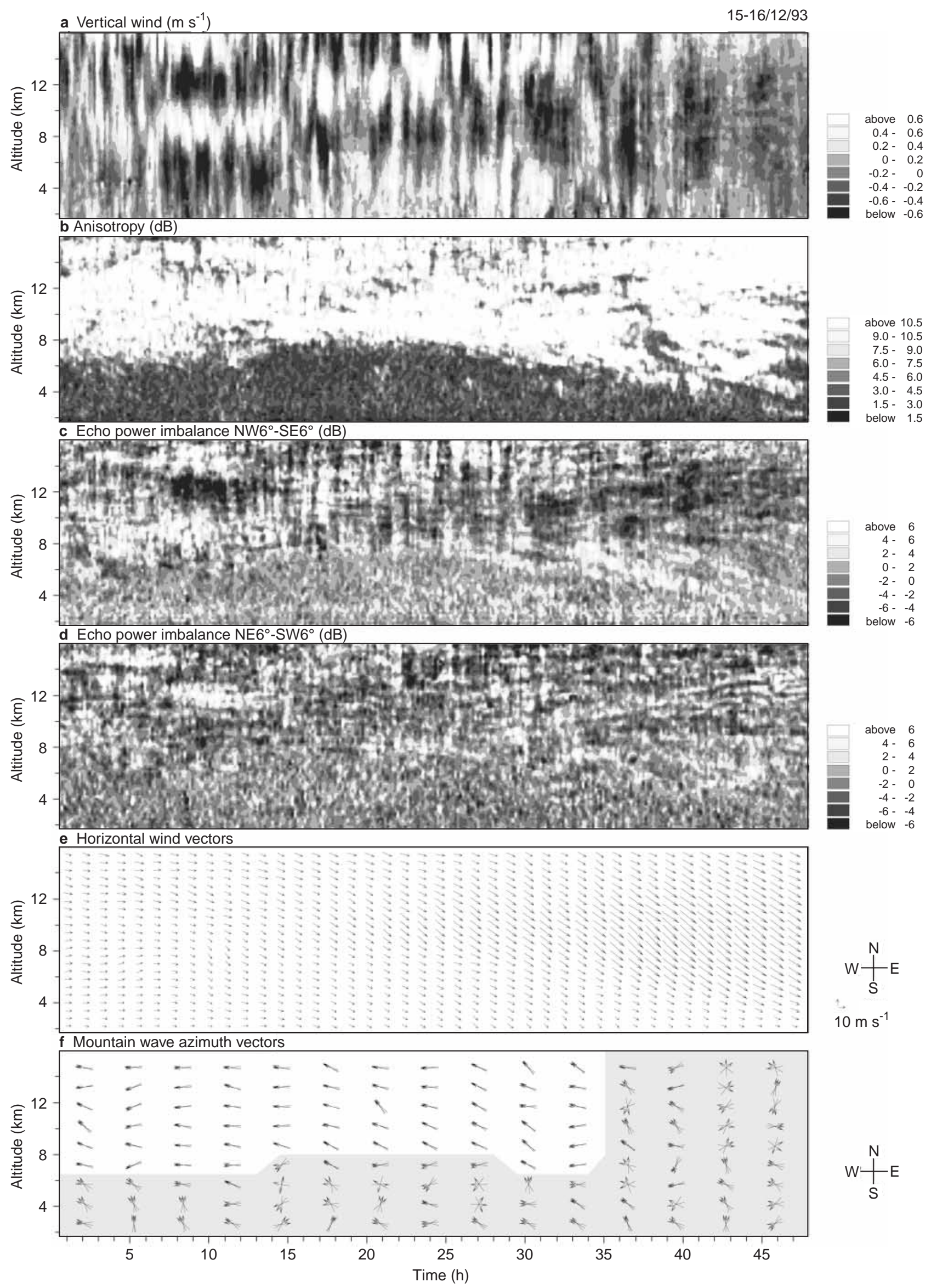

Fig. 7a-f. As Fig. 4, for 15-16 December 1993 
a Vertical wind $\left(\mathrm{m} \mathrm{s}^{-1}\right)$
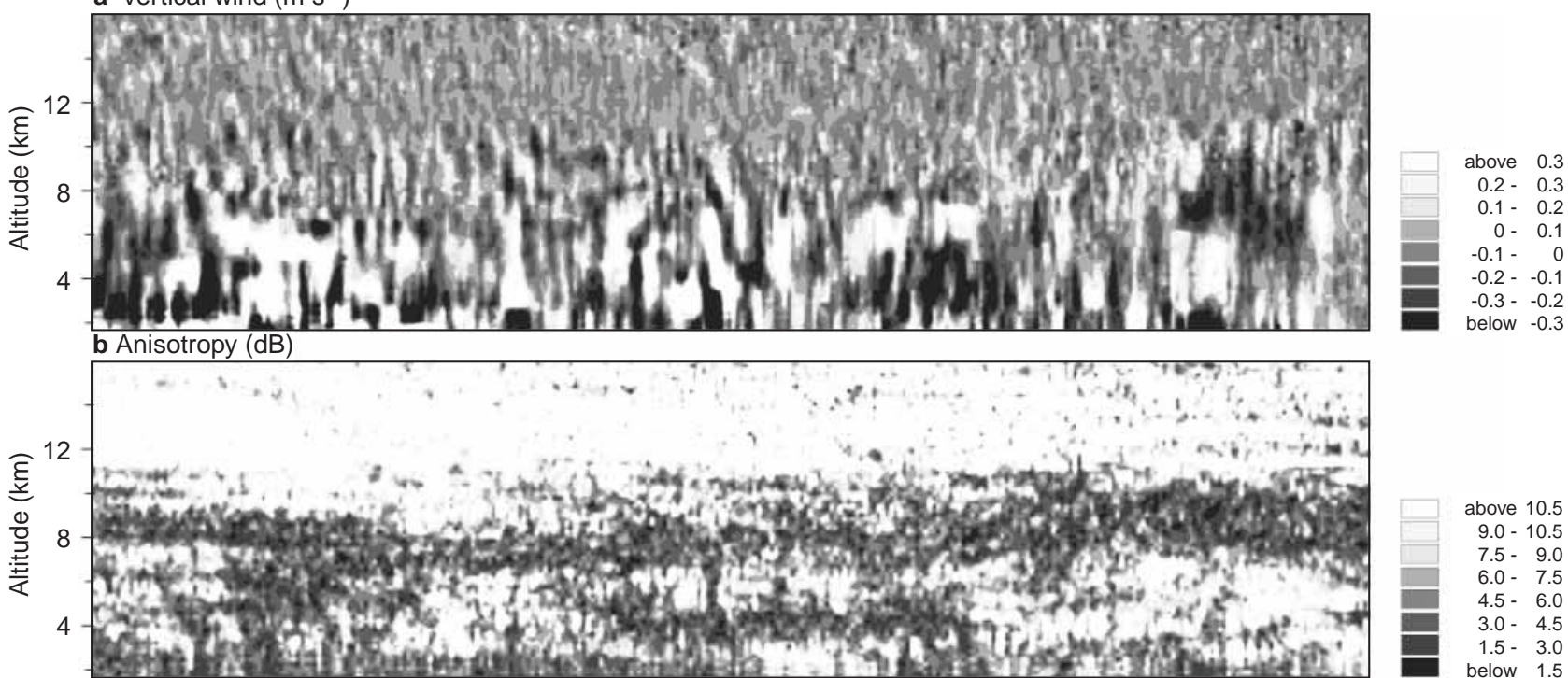

c Echo power imbalance $\mathrm{NW6}^{\circ}-\mathrm{SE}^{\circ}(\mathrm{dB})$

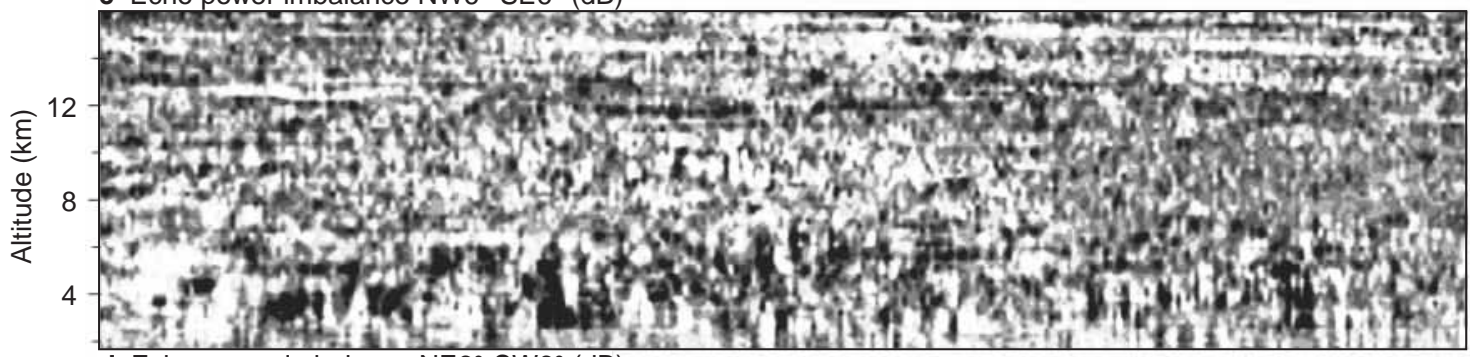

d Echo power imbalance NE6 ${ }^{\circ}-S W 6^{\circ}(\mathrm{dB})$

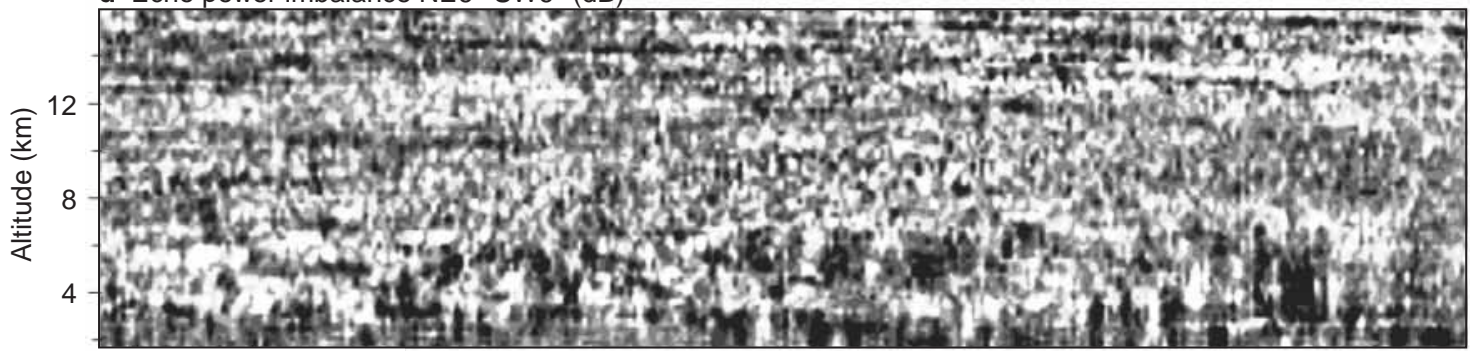

e Horizontal wind vectors
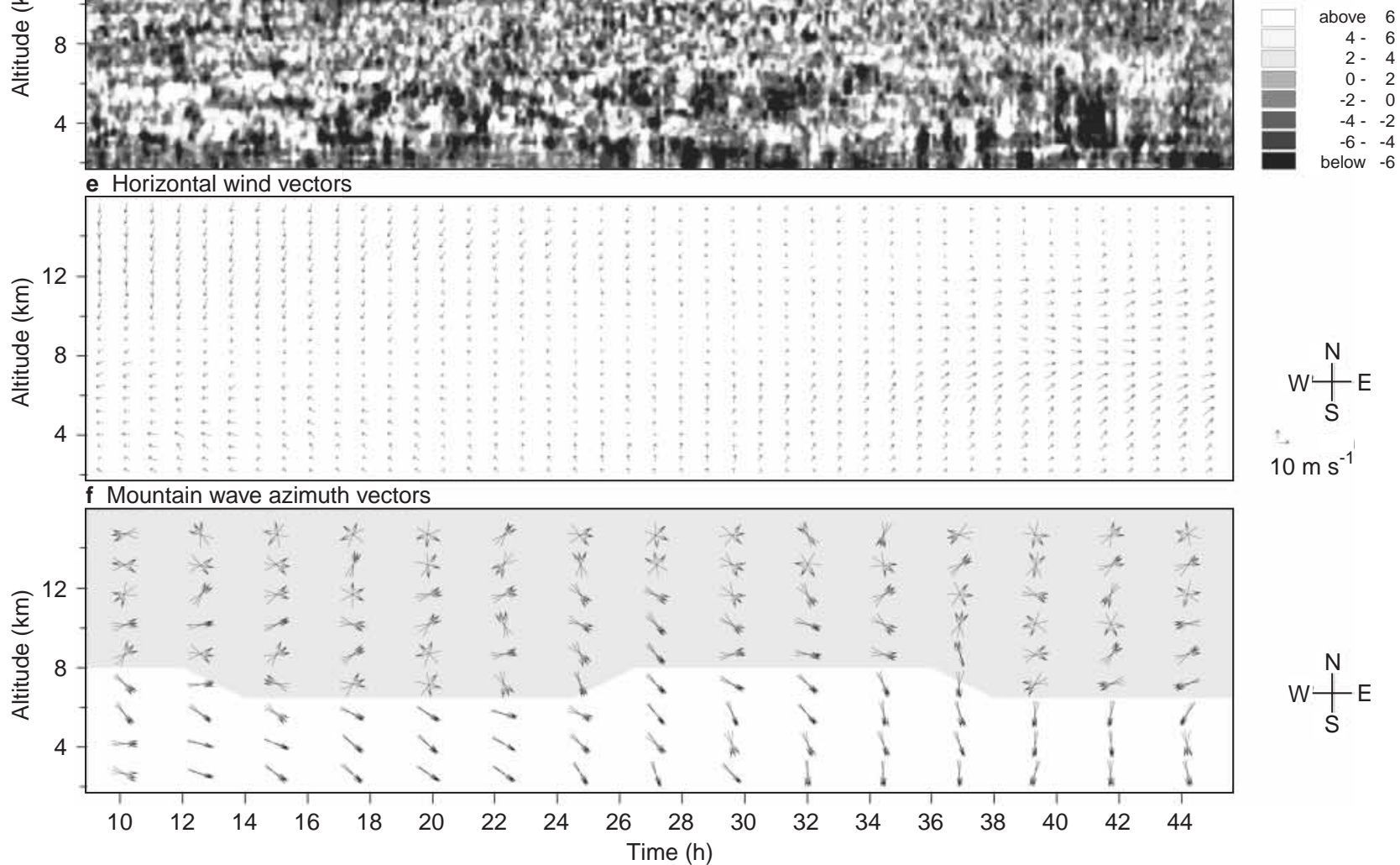

$10 \mathrm{~m} \mathrm{~s}^{-1}$

$\left.W\right|_{S} ^{N} E$

Fig. 8. As Fig. 4, for $28-29$ October 1997 


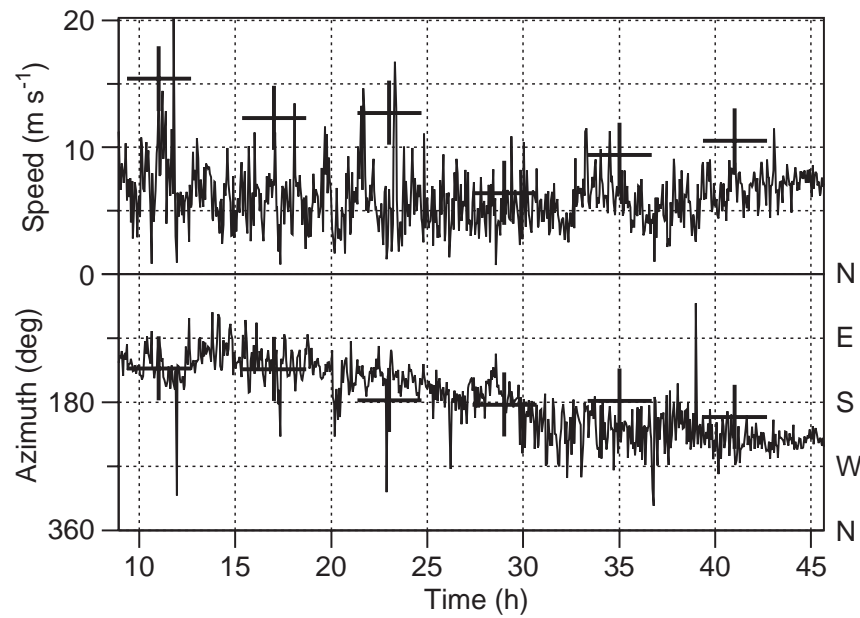

Fig. 9. Comparison of the wind speed and direction measured in the lowest radar height gates at $\sim 2 \mathrm{~km}$ altitude, and by six radiosondes each averaged between $200-1000 \mathrm{~m}$ altitude. Crosses give the radiosonde measurements. 'Azimuth' refers to the direction the wind blows from, measured clockwise from north

pointing misalignment (Huaman and Balsley, 1996). The mean profile of vertical wind measured by the Aberystwyth MST radar is shown in Fig. 10. In addition to the vertical-beam measurement, the $\mathrm{NE}^{\circ}-\mathrm{SW} 6^{\circ}$ and $\mathrm{NW}^{\circ}-\mathrm{SE}^{\circ}$ beam pairs are used to calculate $\overline{\boldsymbol{W}}$, assuming that $\boldsymbol{W} \approx\left(v_{\mathrm{NE} 6^{\circ}}+v_{\mathrm{SW} 6^{\circ}}\right) /\left(2 \cos 6^{\circ}\right)$ and $\boldsymbol{W} \approx$ $\left(v_{\mathrm{NW} 6^{\circ}}+v_{\mathrm{SE} 6^{\circ}}\right) /\left(2 \cos 6^{\circ}\right)$ respectively, where $v$ is the line-of-sight velocity in the relevant beam. In Fig. 10a, the three profiles only use data from when all five beams $\left(\mathrm{NW}^{\circ}, \mathrm{NE}^{\circ}, \mathrm{SE}^{\circ}, \mathrm{SW}^{\circ}\right.$ and vertical) are available, whereas profiles in Fig. 10b use data from whenever the relevant beam (or beam pair) is available. While the radar is not always run in 5-beam mode, the vertical beam is almost always used, so there is a very large amount of vertical-beam data in Fig. 10b, more than $15,000 \mathrm{~h}$ (600 days), almost the entire output of the Aberystwyth MST radar during June 1990-December 1997. For the other profiles in Figs. 10a, b, approximately half this amount of data is available. Profiles obtained by splitting the data into two roughly equal halves (1990-1994 and 1995-1997), averaging each separately, are almost identical to Fig. 10, which gives further confidence in these results.

All the profiles show a similar form, although with some quantitative differences perhaps related to the layer-tilting discussed earlier. The mean vertical wind is found to be as much as $3 \mathrm{~cm} \mathrm{~s}^{-1}$ downward in the troposphere, and more weakly upward in the stratosphere, which agrees with many of the previous studies of $\overline{\boldsymbol{W}}$ already cited. The upward $\overline{\boldsymbol{W}}$ in the stratosphere is not, however, consistent with the model of Nastrom and VanZandt (1994), in which gravity waves, propagating upward from the boundary layer, can introduce a downward bias to radar $\overline{\boldsymbol{W}}$ measurements. A change of sign near $10 \mathrm{~km}$ is described by Yoe and Rüster (1992) and Muschinski (1996); however, in Fig. 10 there are further reversals in the sign of $\overline{\boldsymbol{W}}$, below $3 \mathrm{~km}$ and $18 \mathrm{~km}$, and these cannot be explained by any of the models discussed.

Although the magnitude and sign of $\bar{W}$ in most of the troposphere and lower stratosphere $(3-18 \mathrm{~km})$ are consistent with other studies, the extra changes of sign at Aberystwyth might indicate a residual mountain-wave component in the $\overline{\boldsymbol{W}}$ profile, i.e. the occurence of different phases of mountain wave above the radar, in terms of both the horizontal and vertical position of the phase fronts, is not random in the available data, so $\overline{\boldsymbol{W}}$ does not tend to zero. There might be a slightly greater probability for mountain waves with a particular

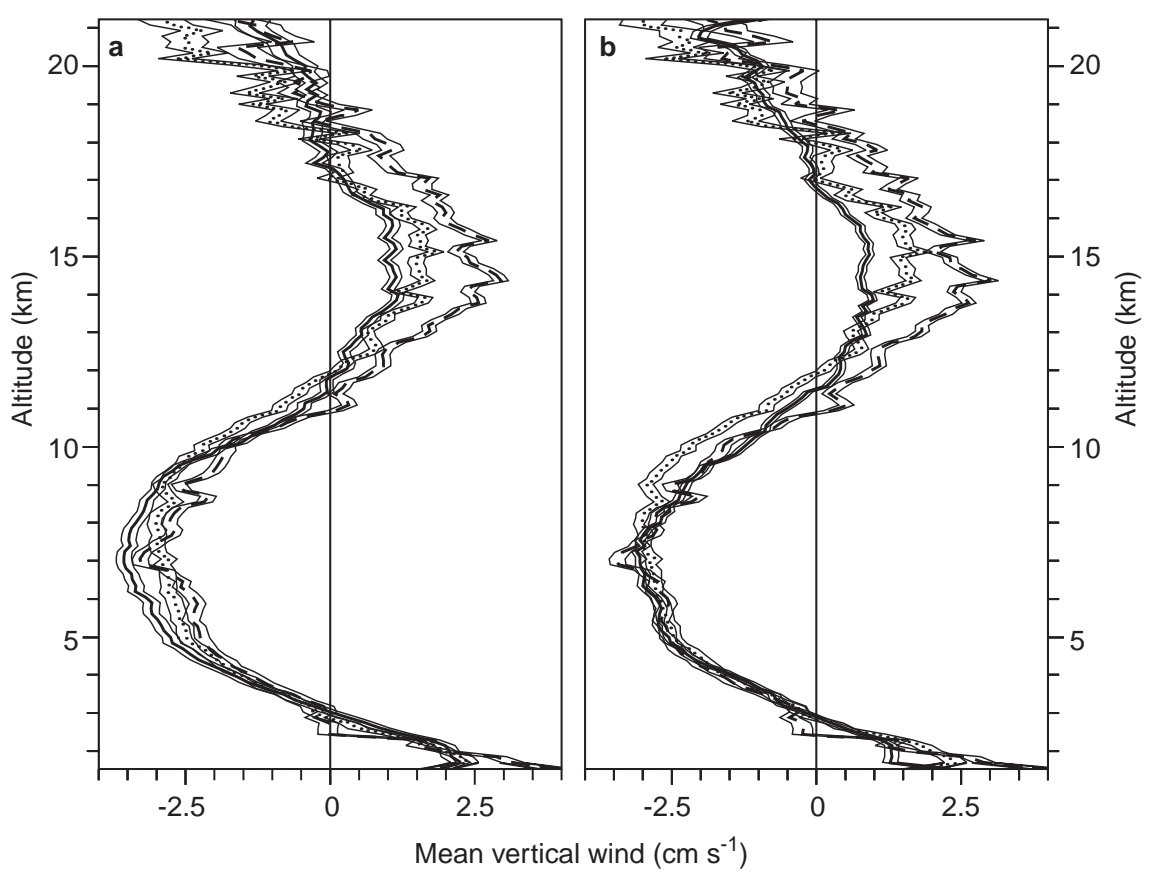

Fig. 10. a,b. Profiles of the mean vertical wind, using almost the entire output of the Aberystwyth MST radar in June 1990 December 1997. Solid, dashed and dotted lines indicate vertical wind measured by the vertical beam, the $\mathrm{NW} 6^{\circ}-\mathrm{SE} 6^{\circ}$ beam pair, and the $\mathrm{NE} 6^{\circ}-\mathrm{SW} 6^{\circ}$ beam pair respectively, a using data when the vertical and all the $6^{\circ}$ beams are available; $\mathbf{b}$ using data whenever the relevant beam or beam pair is available. Standard errors are also shown. 
vertical wavelength and phase, similar to those in Fig. 10 , to occur above the radar, perhaps because of the prevailing winds and the topography around the radar (e.g. Caccia et al., 1997). The good agreement of $\overline{\boldsymbol{W}}$ between $3-18 \mathrm{~km}$ with previous studies might then be no more than a strange coincidence.

\section{Conclusions}

Imbalances of VHF echo power between symmetric pairs of radar beams, caused by tilting of aspectsensitive layers by mountain waves, can be used to calculate the orientation of the wave pattern. Information about the tilt angles of the scattering layers, or the aspect sensitivity, is not required. In the most basic method, wave azimuth is given by the vector $\left[\left(\boldsymbol{P}_{\mathrm{E}}-\boldsymbol{P}_{\mathrm{W}}\right),\left(\boldsymbol{P}_{\mathrm{N}}-\boldsymbol{P}_{\mathrm{S}}\right)\right]$, where $\boldsymbol{P}_{\mathrm{N}}, \boldsymbol{P}_{\mathrm{S}}, \boldsymbol{P}_{\mathrm{E}}, \boldsymbol{P}_{\mathrm{W}}$ are radar echo powers, measured in $\mathrm{dB}$, in beams pointed away from zenith by the same angle towards north, south, east and west respectively. An improved method uses the vertical-wind perturbations of mountain waves as a reference, to find the relative mean magnitudes of the mountain-wave contributions to power imbalances $\left(\boldsymbol{P}_{\mathrm{E}}-\boldsymbol{P}_{\mathrm{W}}\right)$ and $\left(\boldsymbol{P}_{\mathrm{N}}-\boldsymbol{P}_{\mathrm{S}}\right)$. It is shown that the mountain-wave azimuth is given by the vector

$$
\left[\overline{\boldsymbol{W}\left(\boldsymbol{P}_{\mathrm{E}}-\boldsymbol{P}_{\mathrm{W}}\right)}, \overline{\boldsymbol{W}\left(\boldsymbol{P}_{\mathrm{N}}-\boldsymbol{P}_{\mathrm{S}}\right)}\right]
$$

where $\boldsymbol{W}$ is the vertical wind velocity. Problems arising if the mountain-wave horizontal wavelength and the radar beam separation are similar are investigated in the Appendix, and found to be not significant provided the wavelength is more than $\approx 3$ times the beam separation. Data from the Aberystwyth MST radar are used to calculate height-time plots of mountain-wave azimuth. In three case studies, the wave vector is usually found to

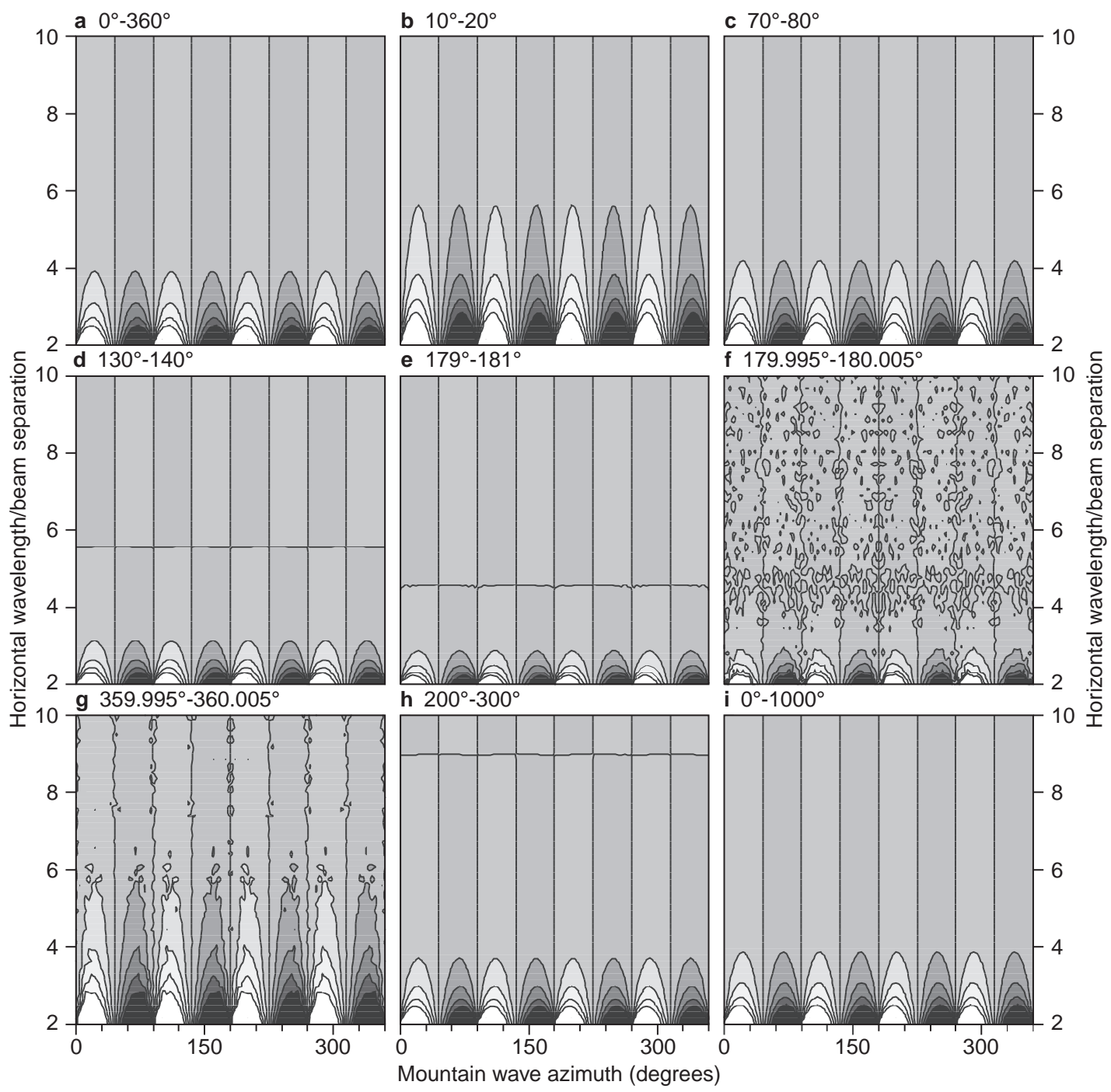

Fig. 11. Error in the calculated mountain-wave azimuth caused by the tilted radar-scattering layers being curved not plane, for various ranges of wave phase. When the horizontal wavelength is much greater than the radar beam separation, the layers can be assumed plane so the error is small. For shorter-wavelength mountain waves, the curvature only becomes important when the wavelength is less than $\approx 3$ times the radar beam separation 
point into the low-level wind, showing variations of not more than a few tens of degrees with altitude.

The mean vertical wind $(\overline{\boldsymbol{W}})$ profile is calculated using more than 600 days of data from the last eight years of Aberystwyth radar operation. While $\overline{\boldsymbol{W}}$ between $3-18 \mathrm{~km}$ is consistent with previous studies, reversals of sign above $18 \mathrm{~km}$ and below $3 \mathrm{~km}$ are not explainable by existing models, but may represent a residual mountainwave component.

Acknowledgements. I am grateful to: the NERC Satellite Receiving Station, Dundee University, Scotland for NOAA satellite images; Neil Lonie for help with obtaining these images; the Meteorological Office for Aberporth radiosonde data; the NERC British Atmospheric Data Centre, at the Rutherford Appleton Laboratory, for data used in Fig. 10; Z. K. Olewicz, MST radar site manager at Capel Dewi; and Dr David Hooper for useful comments on the manuscript. The Aberystwyth MST radar is a national facility of NERC (Natural Environment Research Council).

Topical Editor F. Vial thanks J. L. Caccia and another referee for their help in evaluating this paper.

\section{Appendix}

The scattering layers above the VHF radar, although tilted, are assumed to be plane and not curved. However, if the horizontal wavelength of the mountain waves is similar to the radar beam separation, then the curvature of the layers is not negligible. To test the effect of curved not plane scattering layers, the mountainwave azimuth is calculated using Eq. (23) with data from an artificial sinusoidal wave pattern. Instead of assuming a single tilt $\delta$ at any given time, local values of $\delta$ are found for each off-vertical beam position, given by the slope of the plane tangent to the layers tilted by the mountain wave at these locations. The layers are still assumed plane over the much smaller width of the radar beam $(\sim 500 \mathrm{~m}$ at altitude $10 \mathrm{~km}$, if the angular beamwidth is $3^{\circ}$ ). Using $\boldsymbol{W} \propto \sin \delta$ to give the vertical wind that would be measured by the vertical beam, and averaging over all phases $(0 \rightarrow 2 \pi)$ of the mountainwave pattern, the difference between the true wave azimuth and that calculated from (23) is plotted in Fig. $11 \mathrm{a}$.

The azimuth error is less than $\pm 10^{\circ}$, provided the horizontal wavelength is more than 3 times the beam separation. The zenith and tilt angles used are $\theta=6^{\circ}$ and $\delta=2^{\circ}$ respectively, although other typical values of $\theta$ and $\delta$ (with $\theta \gg \delta$ ) give similar results. Considering, for example, low-level trapped lee waves at $2 \mathrm{~km}$ altitude, the horizontal separation of two $6^{\circ}$ radar beams is $0.4 \mathrm{~km}$, so the lee wave length would need to be $1.2 \mathrm{~km}$ or greater for the power-imbalance method to work. For mountain waves at $10 \mathrm{~km}$ altitude, the beam separation is $2.1 \mathrm{~km}$, requiring a wavelength at least $6.3 \mathrm{~km}$. For typical mountain waves (e.g. Shutts and Broad, 1993; Shutts, 1997) these conditions are not very restrictive, and the assumption of flat, tilted scattering layers in Eq. (23) is valid. The close agreement between the true azimuth and that calculated from Eq. (23), in the limit where the wavelength is much greater than the beam separation (i.e. the upper half of Fig. 11a), confirms the validity of the approximations used to derive Eqs. (9) and (10). Figure 11b-i shows tests using averages over various phase intervals, including both some typical examples, and other more extreme ones with some intervals much shorter than $360^{\circ}$ (e.g. Fig. $11 \mathrm{~b})$ which would almost never occur in nature. When the wave pattern is positioned with a region of greatest upward or downward displacement directly above the vertical radar beam (phase $0^{\circ}$, or $180^{\circ}$ ), the powerimbalance method must fail since $\boldsymbol{D}_{1 \mathrm{w}}$ and $\boldsymbol{D}_{2 \mathrm{w}}$, in Eqs. (2) and (3), both become zero and the azimuth is undefined; however, with an infinitely small variation of wave phase (e.g. Fig. 11f, g), the power imbalances become non-zero and the method works, so this problem should not occur with real data (although, in practice, the power imbalances and vertical wind in Fig. 11f, g would be too small to measure by VHF radar). The azimuth error is increased for certain small phase intervals (Fig. 11b, g), but Figs. 4, 7 and 8 show how it is possible, using real data, to average over larger intervals so that the error will be much reduced, and comparable to Fig. 11a, h, i. Overall, it appears that curvature of the scattering layers is not a serious problem provided the horizontal wavelength is more than $\approx 3$ times the beam separation.

Any sensitivity to the range of wave phases in the height-time averaging interval can be identified in real data; for example, in Figs. 4f, 7f and 8f, each calculated wave vector is an independent sample of the mountain wave pattern, containing a different range of wave phases, yet adjacent wave azimuth vectors agree, which gives confidence in the results. The averaging height/ time interval can be increased until the calculated azimuth is insensitive to the exact interval being used, and adjacent arrows agree; the azimuth could even be assumed constant with height, and only the time dependence calculated. Further tests of the powerimbalance method are also made by R.M. Worthington, R.D. Palmer and S. Fukao, 1998, 'An investigation of tilted aspect-sensitive scatterers in the lower atmosphere, using the MU and Aberystwyth VHF radars', manuscript in press, Radio Science, and it is applied by R. M. Worthington, 1998, 'Alignment of mountain wave patterns above central Wales: a VHF radar study during 1990-1998', manuscript submitted to Journal of Geophysical Research.

Note that the error in calculated azimuth is zero when $\phi=0^{\circ}, 45^{\circ}, 90^{\circ}, 135^{\circ}, 180^{\circ}, 225^{\circ}, 270^{\circ}, 315^{\circ}$ and $360^{\circ}$, even when the layers are curved not plane, over the range of wavelengths shown in Fig. 11. When the scattering layers are tilted and curved by a gravity wave with $\phi=0^{\circ}$ or $180^{\circ}$, the power imbalance between $\mathrm{E}$ and $\mathrm{W}$ beams must be zero, so the calculated azimuth can only lie $\mathrm{N}-\mathrm{S}$, which is correct. For $\phi=90^{\circ}$ and $270^{\circ}$, the N-S power imbalance must be zero, and the calculated azimuth must lie E-W. For $\phi=45^{\circ}, 135^{\circ}$, $225^{\circ}$ and $315^{\circ}$, the error introduced by the curvature of layers has an identical effect on the $\mathrm{N}-\mathrm{S}$ and $\mathrm{E}-\mathrm{W}$ power imbalances by symmetry, so they remain equal, causing no error in the azimuth calculation. Therefore, even in 
atmospheric conditions where several assumptions of Sect. 3.1 may be unusually poor, e.g. the layers are curved, or the gradient of echo power with zenith angle cannot be approximated over a small range as linear, the method given by Eq. (23) is constrained to remain accurate to within $45^{\circ}$, and the calculation of mountainwave azimuth is robust.

\section{References}

Abramowitz, M., and I. A. Stegun, Handbook of mathematical functions, Dover, New York, 1965.

Bacmeister, J. T., Mountain-wave drag in the stratosphere and mesosphere inferred from observed winds and a simple mountain-wave parameterization scheme, J. Atmos. Sci., 50, 377-399, 1993.

Caccia, J.-L., B. Benech, and V. Klaus, Space-time description of nonstationary trapped lee waves using ST radars, aircraft, and constant volume balloons during the PYREX experiment, J. Atmos. Sci., 54, 1821-1833, 1997.

Dalaudier, F., C. Sidi, M. Crochet, and J. Vernin, Direct evidence of "sheets" in the atmospheric temperature field, J. Atmos. Sci., 51, 237-248, 1994.

Elkhalfi, A., and B. Carissimo, Numerical simulations of a mountain wave observed during the "Pyrenees Experiment": hydrostatic/non hydrostatic comparison and time evolution, Beitr. Phys. Atmos., 66, 183-200, 1993.

Fukao, S., M. F. Larsen, M. D. Yamanaka, H. Furukawa, T. Tsuda, and $\mathbf{S}$. Kato, Observations of a reversal in long-term average vertical velocities near the jet stream wind maximum, Mon. Weather Rev., 119, 1479-1489, 1991.

Hocking, W. K., and A. M. Hamza, A quantitative measure of the degree of anisotropy of turbulence in terms of atmospheric parameters, with particular reference to radar studies, J. Atmos. Solar-Terr. Phys., 59, 1011-1020, 1997.

Hocking, W. K., R. Rüster, and P. Czechowsky, Absolute reflectivities and aspect sensitivities of VHF radio wave scatterers measured with the SOUSY radar, J. Atmos. Terr. Phys., 48, 131-144, 1986.

Hooper, D., and L. Thomas, Aspect sensitivity of VHF scatterers in the troposphere and stratosphere from comparisons of powers in off-vertical beams, J. Atmos. Terr. Phys., 57, 655-663, 1995.

Huaman, M. M., and B. B. Balsley, Long-term average vertical motions observed by VHF wind profilers: the effect of slight antenna-pointing inaccuracies, J. Atmos. Ocean. Tech., 13, 560569,1996

Jain, A. R., Y. J. Rao, and P. B. Rao, Aspect sensitivity of the received radar backscatter at VHF: preliminary observations using the Indian MST radar, Radio Sci., 32, 1249-1260, 1997.

Larsen, M. F., and R. D. Palmer, A relationship between horizontal flow gradients, in-beam incidence angles, and vertical velocities, Radio Sci., 32, 1269-1277, 1997.

Larsen, M. F., and J. Röttger, VHF radar measurements of inbeam incidence angles and associated vertical-beam radial velocity corrections, J. Atmos. Ocean. Tech., 8, 477-490, 1991.

Luce, H., M. Crochet, F. Dalaudier, and C. Sidi, Interpretation of VHF ST radar vertical echoes from in situ temperature sheet observations, Radio Sci., 30, 1003-1025, 1995.

Mitchell, R. M., R. P. Cechet, P. J. Turner, and C. C. Elsum, Observation and interpretation of wave clouds over Macquarie Island, Q. J. R. Meteorol. Soc., 116, 741-752, 1990.
Muschinski, A., Possible effect of Kelvin-Helmholtz Instability on VHF radar observations of the mean vertical wind, J. Appl. Meteorol., 35, 2210-2217, 1996.

Nastrom, G. D., and T. E. VanZandt, Mean vertical motions seen by radar wind profilers, J. Appl. Meteorol., 33, 984-995, 1994.

Nastrom, G. D., and F. D. Eaton, Variations of winds and turbulence seen by the $50-\mathrm{MHz}$ radar at White Sands Missile Range, New Mexico, J. Appl. Meteorol., 34, 2135-2148, 1995.

Ordnance Survey, Pathfinder Map 926 (Aberystwyth), 1:25000 scale, Ordnance Survey, Southampton, England, 1987a.

Ordnance Survey, Pathfinder Map 927 (Tal-y-bont and Ponterwyd), 1:25000 scale, Ordnance Survey, Southampton, England, 1987b.

Pepler, S. J., G. Vaughan, and D.A. Hooper, Detection of turbulence around jet streams using a VHF radar, $Q . J . R$. Meteorol. Soc., 124, 447-462, 1998.

Prichard, I. T., and L. Thomas, Radar observations of gravity-wave momentum fluxes in the troposphere and lower stratosphere, Ann. Geophysicae, 11, 1075-1083, 1993.

Prichard, I. T., L. Thomas, and R. M. Worthington, The characteristics of mountain waves observed by radar near the west coast of Wales, Ann. Geophysicae, 13, 757-767, 1995.

Ralph, F. M., P. J. Neiman, T. L. Keller, D. Levinson, and L. Fedor, Observations, simulations, and analysis of nonstationary trapped lee waves, J. Atmos. Sci., 54, 1308-1333, 1997.

Röttger, J., C. H. Liu, J. K. Chao, A. J. Chen, C. J. Pan, and I.-J. Fu, Spatial interferometer measurements with the Chung-Li VHF radar, Radio Sci., 25, 503-515, 1990.

Shutts, G., Gravity-wave drag parameterization over complex terrain: The effect of critical-level absorption in directional wind-shear, Q. J. R. Meteorol. Soc., 121, 1005-1021, 1995.

Shutts, G., Operational lee-wave forecasting, Meteorol. Appl., 4, 23-35, 1997.

Shutts, G., and A. Broad, A case study of lee waves over the Lake District in northern England, Q. J. R. Meteorol. Soc., 119, 377408, 1993.

Simard, A., and W. R. Peltier, Ship waves in the lee of isolated topography, J. Atmos. Sci, 39, 587-609, 1982.

Tsuda, T., T. E. VanZandt, and H. Saito, Zenith-angle dependence of VHF specular reflection echoes in the lower atmosphere, $J$. Atmos. Solar-Terr. Phys., 59, 761-775, 1997a.

Tsuda, T., W. E. Gordon, and H. Saito, Azimuth angle variations of specular reflection echoes in the lower atmosphere observed with the MU radar, J. Atmos. Solar-Terr. Phys., 59, 777-784, 1997b.

Worthington, R. M., and L. Thomas, The measurement of gravity wave momentum flux in the lower atmosphere using VHF radar, Radio Sci., 31, 1501-1517, 1996a.

Worthington, R. M., and L. Thomas, Radar measurements of critical-layer absorption in mountain waves, $Q . J . R$. Meteorol. Soc., 122, 1263-1282, 1996b.

Worthington, R. M., and L. Thomas, Long-period unstable gravitywaves and associated VHF radar echoes, Ann. Geophysicae, 15, 813-822, 1997.

Worthington, R. M., and L. Thomas, The frequency spectrum of mountain waves, Q. J. R. Meteorol. Soc., 124, 687-703, 1998.

Yoe, J. G., and R. Rüster, VHF Doppler radar observations of vertical velocities in the vicinity of the jet stream, Mon. Weather Rev., 120, 2378-2382, 1992.

Yoe, J. G., P. Czechowsky, R. Rüster, and G. Schmidt, Spatial variability of the aspect sensitivity of VHF radar echoes in the troposphere and lower stratosphere during jet stream passages, Ann. Geophysicae, 12, 733-745, 1994. 